\title{
ОСНОВНЫЕ НАПРАВЛЕНИЯ ИСПОЛЬЗОВАНИЯ МИКРОВОЛНОВОГО ИЗЛУЧЕНИЯ ПРИ ПЕРЕРАБОТКЕ РАСТИТЕЛЬНОГО СЫРЬЯ (ОБЗОР)
}

\author{
() В.И. Маркин", М.Ю. Чепрасова, Н.Г. Базарнова \\ Алтайский государственный университет, пр. Ленина, 61, Барнаул, 656049 \\ (Россия), e-mail: markin@chemwood.asu.ru
}

\begin{abstract}
Использование микроволнового излучения в химии растительного сырья в последнее десятилетие привлекает внимание все большего числа ученых. Обзор посвящен анализу публикаций в данной области за последние годы, число которых растет экспоненциально. Рассмотрены основные области применения микроволнового излучения в химии и технологии растительного сырья: экстракция из природных растительных объектов низкомолекулярных соединений самых разных классов как в индивидуальном состоянии, так и виде композиций (например, эфирные масла); выделение высокомолекулярных структурных биополимеров (целлюлоза, лигнин, гемицеллюлозы); процессы высушивания растительных объектов; пиролиз древесины; гидролиз высокомолекулярных компонентов растительного сырья; химическое модифицирование биополимеров растительного происхождения с целью получения простых и сложных эфиров, а также других производных; химическое модифицирование растительного сырья без предварительного разделения на отдельные компоненты и некоторые другие процессы. Показана эффективность микроволнового излучения в данных процессах. Отмечено, что микроволновое излучение в целом значительно ускоряет проводимый процесс и значительно снижает затраты электроэнергии. Приведены примеры реализации описанных процессов в промышленности. Процессы и механизмы, происходящие при воздействии на растительное сырье микроволнового излучения в настоящее время недостаточно изучены и требуют дальнейших исследований.

Ключевые слова: микроволновое излучение, растительное сырье, древесина, целлюлоза, лигнин, гемицеллюлозы, экстрактивные вещества, эфирные масла, ионные жидкости, зеленая химия, химическое модифицирование, высушивание, пиролиз, гидролиз, делигнификация.
\end{abstract}

\section{Введение}

Решение проблемы комплексной переработки растительной биомассы является одной из самых востребованных задач настоящего времени. Важным при этом является использование новых химических, физикохимических, физических и биологических подходов при обработке растительного возобновляемого сырья, которые бы отвечали принципам зеленой химии $[1,2]$. Одним из возможных путей достижения поставленной задачи является использование микроволнового излучения (МВИ). Интерес к применению МВИ в науке и промышленности с каждым годом вызывает все больший интерес. Несмотря на то, что микроволновое излучение активно используется достаточно давно (с 40-х гг. XX в.) в военной области, промышленности, научный интерес к влиянию на вещество и возможность его использования в химии появился сравнительно недавно [3].

Область спектра электромагнитного излучения в интервале частот 300 ГГц - 300 МГц (длина волны от 1 мм до 1 м) принято назвать микроволновой. Она располагается в интервале между инфракрасным и радиочастотным диапазонами. В настоящее время в научной литературе наиболее распространен термин «микроволны». Ранее также широко использовался термин «сверхвысокая частота» (СВЧ), который определяет тот же диапазон частот. В соответствии с принятыми международными соглашениями для использования

Маркин Вадим Иванович - доцент кафедры органической химии, кандидат химических наук,

тел.: (3852) 36-95-37, e-mail: markin@ chemwood.asu.ru Чепрасова Марина Юрьевна - преподаватель кафедры органической химии, кандидат химических наук,

тел.: (3852) 36-95-37, e-mail: marinacheprasova@ yandex.ru Базарнова Наталья Григорьевна - заведующая кафедрой органической химии, профессор, доктор химических наук, тел.: (3852) 36-95-37, e-mail: bazarnova@chem.asu.ru в быту, промышленности и медицине регламентирован ряд частот (табл. 1), причем некоторые из них используются, только в отдельных странах [46]. В большинстве микроволновых установок мира (прежде всего бытовые микроволновые печи) используется частота 2450 МГц. Данная частота применяется в большинстве случаев для проведения и изучения химических реакций $[3,7]$.

\footnotetext{
* Автор, с которым следует вести переписку.
} 
Распределение частот для промышленных, медицинских и научных целей в диапазоне 433,92 до 40000 МГц

\begin{tabular}{|c|c|c|}
\hline $\begin{array}{c}\text { Частота, } \\
\text { МГц }\end{array}$ & $\begin{array}{l}\text { Допустимое } \\
\text { отклонение }\end{array}$ & Страна использования \\
\hline 434 & $0,2 \%$ & $\begin{array}{c}\text { Австрия, Нидерланды, Порту- } \\
\text { галия, Германия, Швейцария }\end{array}$ \\
\hline 896 & 10 МГц & Великобритания \\
\hline 915 & 13 МГц & Северная и Южная Америка \\
\hline 2375 & 50 МГц & $\begin{array}{c}\text { Албания, Болгария, Венгрия, } \\
\text { Румыния, Словакия, Чехия, } \\
\text { Россия }\end{array}$ \\
\hline 2450 & 50 МГц & $\begin{array}{c}\text { Весь мир, кроме случаев, ко- } \\
\text { гда используется } 2375 \text { МГц }\end{array}$ \\
\hline 3390 & $0,6 \%$ & Нидерланды \\
\hline 5800 & 5 МГц & Весь мир \\
\hline 6780 & $0,6 \%$ & Нидерланды \\
\hline 24150 & 25 МГц & Весь мир \\
\hline 40680 & 25 МГц & Великобритания \\
\hline
\end{tabular}

В настоящее время накоплен большой опыт по использованию микроволнового излучения в различных областях науки, техники, промышленности, медицины, сельского хозяйства и в быту. Большинство данных областей достаточно подробно освещены в мировой литературе. Среди крупных монографий в данной области следует отметить работы [4, 5, 8-15]. Кроме того, издается ряд специализированных журналов, посвященных исследованиям по использованию микроволновой энергии в науке и технике. Наиболее известными и авторитетными являютcя: Microwave Journal (http://www.microwavejournal.com/), International Journal of Microwave Science and Technology (http://www.hindawi.com/journals/ijmst/), Jour-

nal of Microwave Power and Electromagnetic Energy (http://jmpee.org/) и ряд других. Однако традиционно работы по применению микроволновой энергии в химии публикуются в химических журналах. Поэтому данные публикации распределены по многим специализированным изданиям в области химии.

Использование микроволнового излучения в химии первоначально ограничивалось пробоподготовкой в аналитической химии при анализе различных объектов (в том числе экстракция) и синтезом некоторых неорганических веществ, сушкой и дегидратацией [16-20].

Началом применения микроволнового излучения в органической химии принято считать классические работы, проведенные в 1986 г. R. Gedye [21] и R. Giguere [22], в которых показано значительное сокращение продолжительности проведения некоторых химических реакций в условиях МВИ по сравнению с условиями традиционного нагрева. К другим преимуществам МВИ также можно отнести экономию электроэнергии, возможность проведения реакций в условиях повышенного давления при температурах, намного превышающих температуру кипения растворителя, или в отсутствие растворителя, возможность получения соединений, недоступных или труднодоступных при использовании других методов активации [23]. С появления первых работ о применении МВИ в химии мы наблюдаем устойчивый рост публикаций в данной области. Анализ публикационной активности ученых (по данным БД Scopus, www.scopus.com), использующих микроволновое излуче-

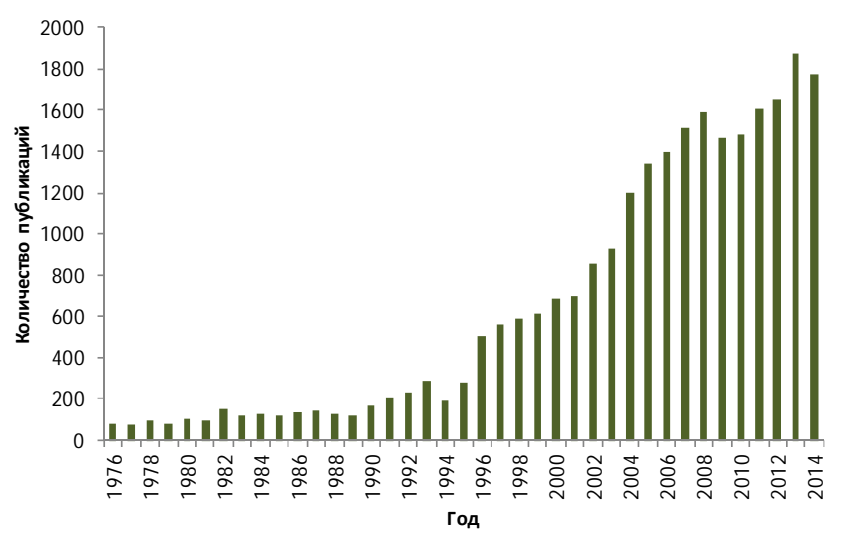

Количество публикаций по использованию микроволнового излучения в химии (по данным базы данных Scopus) ние в различных областях химии, наглядно иллюстрирует изменение числа публикаций (рис.), которые посвящены применению МВИ в различных направлениях химии. Среди наиболее значимых, в которых представлены основные результаты, достигнутые в этой области за последние годы, можно привести [7, 23-28].

Достаточно активно МВИ в последние годы стало использоваться в химии полимеров [29], и в частности в области химии целлюлозы и древесины [15, 30], а также в химии низкомолекулярных соединений растительного сырья [31-33].

Цель настоящей работы - дать обзор литературы, посвященной последним достижениям в области использования микроволнового излучения в химии растительного сырья.

\section{Выделение низкомолекулярных компонентов}

Микроволновое излучение достаточно активно используется при экстракции различных низкомолекулярных органических соединений из природного органического сырья, и прежде всего растительного [34-37]. Известны примеры выделения групп веществ и отдельных соединений, принадлежащих к таким 
классам, как фенольные соединения и флавоноиды [38-45] (корилагин и гераниин [46]), ксантоноиды (мангиферин [47]), сапонины [48] (лупеол [49], бетулин [50]), каротиноиды [51], липиды [52], лигнаны [53], углеводы [54], урсоловая и олеановая кислоты [55, 56], пентациклические терпены [57], терпеноиды (соланесол [58]) и многие другие вещества (например, 6-гингерол [59]).

В качестве перспективного научного направления «зеленой химии» в последние годы активно разрабатывается использование в качестве растворителя различных соединений и материалов (в том числе и растительных объектов) ионных жидкостей (ИЖ). Сочетание использования ионных жидкостей и микроволнового излучения для извлечения экстрактивных веществ из растительного сырья является весьма перспективным. В работах $[41,53,60-62]$ приведены некоторые примеры проведенных исследований.

Также подробно описаны простые ИЖ, такие как $\left[\mathrm{C}_{4} \mathrm{mim}\right][\mathrm{Br}],\left[\mathrm{C}_{4} \mathrm{mim}\right]\left[\mathrm{BF}_{4}\right],\left[\mathrm{C}_{10} \mathrm{mim}_{[}\right]\left[\mathrm{BF}_{4}\right]$, [Allmim] $\left[\mathrm{BF}_{4}\right]$, они хорошо изучены как хорошие растворяющие системы, с помощью которых можно эффективно извлекать из растительного сырья различные соединения, например кверцетин из Toona sinensis [63], подофиллотоксин из Dysosma versipellis, Sinopodophyllum hexandrum и Diphylleia sinensis [64], рутина из Saururus chinensis (Lour.) Bail. (S. chinensis) и Flos Sophorae [65]. Как отмечают авторы, основным преимуществом использования микроволнового излучения является быстрое проведение процесса экстракции.

Микроволновое излучение позволяет увеличить выход эфирного масла при его получении из различного растительного сырья с использованием растворителей, «прозрачных» к действию МВИ [66]. Авторами показано, что использование МВИ при получении эфирного масла данным способом позволяет значительно сократить общую продолжительность процесса. Использование микроволнового излучения позволяет очень быстро и эффективно выделять эфирные масла из разного растительного сырья без сложного дополнительного оборудования в бытовой микроволновой печи [67].

Использование микроволнового излучения при получении эфирного масла парогидродистилляцией вызывает не только быстрый объемный нагрев всей массы, но способствует более сильной деструкции исходного растительного материала, что вызывает более быстрое и полное высвобождение низкомолекулярных соединений. Поэтому состав эфирного масла, полученного при использовании микроволнового нагрева, может значительно отличаться от полученного традиционным способом [68].

Для эффективного извлечения летучих низкомолекулярных органических соединений из растительного сырья был разработан способ дистилляции и одновременной экстракции органическим растворителем с использованием микроволнового излучения [69]. Предложено аппаратурное решение для обеспечения удобного и быстрого проведения процесса. На примере Zygophyllum album L. показано, что использование микроволнового излучения позволяет значительно сократить процесс извлечения (30 мин против 3 ч) по сравнению с традиционным способом, и при этом для экстракции требуется меньшее количество растворителя. Однако, как отмечают авторы, состав полученных образцов эфирных масел сильно отличается по составу.

В работе [70] проведено сравнение методов получения эфирного масла парогидродистилляцией из свежей мяты (Mentha piperita L.) и метода сухой перегонки (без использования растворителя) с использованием МВИ. При выделении эфирного масла обоими методами обнаружено что при микроволновом излучении свежие листья благодаря высокому содержанию воды быстро нагреваются, что приводит к разрыву клеточных стенок и быстрому высвобождению летучих компонентов. Это приводит к быстрому протеканию процесса и более высокому выходу эфирного масла. Однако использование высокой мощности МВИ может привести к снижению содержания основных наиболее ценных компонентов эфирного масла.

В работе [71] был разработан новый способ получения эфирных масел без использования растворителя. Порошок карбонильного железа тщательно смешивают с образцом высушенного растительного материала растения, помещают в реактор и подвергают микроволновому облучению при мощности 350 Вт в течение 12 мин. Эфирные масла скапливаются в свободном пространстве реакционного сосуда. С помощью микрошприца в реакционное пространство водится капля декана так, чтобы она была на кончике иглы. После экстракции в течение 7 мин капля втягивается обратно в шприц и затем в виде раствора вводится непосредственно в ГЖ-МС-хроматограф. По сравнению с традиционным методом получения эфирных масел (парогидродистилляции) предложенный способ требует очень маленького количества образца растительного материала и меньшей продолжительности извлечения эфирных масел. Сравнение состава эфирных масел Eugenia caryophyllata Thunb., полученных данным способом и методом парогидродистилляции, показало их практически полную идентичность. Аналогичное ГХ-МС-исследование проведено по изучению эфирного масла Nepeta crispa Willd. [72].

Также были проведены исследования по выделению эфирных масел с использованием микроволнового излучения из других растительных объектов, например: лимонник китайский (Schisandra chinensis 
(Turcz.) Baill.) [73], грецкий opex (Juglans regia L.) [74], щитовник пахучий (Dryopteris fragrans) [75], полынь Черняева Artemisia tschernieviana [76], мелисса лекарственная (Melissa officinalis L.), лавр благородный (Laurus nobilis L.) [77], кипарисовик туполистный (Chamaecyparis obtusa) [78], различных видов мяты [79] и других растений [80-83].

Для экстракции эфирных масел под воздействием микроволнового излучения возможно использование ИЖ [84]. Сравнение экстракционных возможностей четырех ионных жидкостей и традиционного метода парогидродистилляции на примере получения эфирного масла из семян Fructus forsythiae показало, что совместное использование микроволнового излучения и ионных жидкостей позволяет увеличить выход $(9,58 \%)$ эфирного масла и сократить продолжительность (29,3 мин) по сравнению с методом гидродистилляции (выход - 4,08\% и продолжительность 100 мин). Кроме того, исследование состава полученных масел показало более высокое содержание ценных кислородсодержащих монотерпенов в масле, полученном экстракцией ионными жидкостями под воздействием микроволнового излучения.

Во всех работах отмечается повышение выхода эфирного масла и значительное сокращение продолжительности процесса.

В работе [85] изучено экстрагирование с использованием микроволнового излучения нафтодиантроновых пигментов (гиперицина и псевдогиперицина) из сырьевой фитомассы зверобоя продырявленного Hypericum perforatum. Установлено, что их максимальное извлечение достигается при применении в качестве экстрагентов 55\%-го этанола или пропанола-2 при гидромодуле, равном 40, при удельной мощности микроволнового излучения 0,0205 Вт/см ${ }^{3}$ при частоте 2450 МГц и продолжительности воздействия МВИ 60 с. В качестве источника микроволнового излучения использовали бытовую микроволновую печь.

Изучен процесс выделения экстрактивных веществ и бетулина из древесины березы [50]. Использование микроволнового излучения позволяет увеличить скорость извлечения бетулина и экстрактивных веществ в 10-15 раз по сравнению с традиционной экстракцией методом настаивания. При этом метод настаивания позволяет получить бетулин с 40\%-м выходом, в то время как применение МВИ увеличивает его до $50 \%$. Показано существование сорбционного эффекта при выделении экстрактивных веществ методом настаивания, который отсутствует при использовании МВИ, что способствует увеличению выхода экстрактивных веществ.

Проведено интересное исследование по изучению влияния микроволнового излучения на процесс ферментативной экстракции полифенолов из отходов скорлупы арахиса [86]. Были определены оптимальные условия: время облучения - 2,6 мин, количество целлюлазы - 0,81 мас\%, рН 5,5 и продолжительность инкубации при $66^{\circ} \mathrm{C}$ в течение 2,0 ч. В данных условиях выход общих полифенолов $-1,75 \pm 0,06 \%$.

\section{Выделение высокомолекулярных компонентов}

Микроволновое излучение предложено использовать для выделения полисахаридов из различных видов растительного сырья [87, 88]. Так, было проведено изучение эффективности использования микроволнового излучения для выделения ксилана из древесины березы по сравнению с традиционным способом его излечения [89]. Изучено влияние продолжительности и мощности облучения на выход ксилана. В качестве источника микроволнового излучения использовалась бытовая микроволновая печь. Максимальный выход ксилана (60\% от содержания ксилана в древесине) получен при использовании минимальной мощности МВИ (110 Вт). Данный факт указывает на активное протекание деструкционных процессов при высокой мощности. Растворимость древесины при 10 мин обработке $\mathrm{NaOH}$ с использованием МВИ при 110 Вт аналогична растворимости древесины при традиционной обработке при $90{ }^{\circ} \mathrm{C}$ в течение 1,5 ч. Однако выход ксилана при использовании МВИ выше. Характеристика осажденного ксилана показала, что выделенный ксилан содержит 68-88\% ксилозы. Молекулярная масса ксилана, извлеченного с использованием МВИ, содержала 60-70\% высокомолекулярной и около 30-40\% низкомолекулярной фракций, в то время как ксилан, выделенный традиционным методом, показал обратную тенденцию. В работе [90] этими же авторами методом полного факторного эксперимента проведена оптимизация процесса выделения ксилана из древесины березы под воздействием микроволнового излучения. Изучено влияние таких факторов, как продолжительность процесса (10-30 мин), концентрация $\mathrm{NaOH}$ (4-8\%), жидкостный модуль (от $1: 8$ до $1: 20$ г/мл), масса образца (5-10 г). Разработаны статистические модели влияния изученных факторов на процесс выделения ксилана. Установлены оптимальные условия для его максимального выхода (72,5\% от теоретического содержания в древесине): 10 г измельченной древесины, 8\%-й раствор $\mathrm{NaOH}$, жидкостный модуль - 1 : 10, продолжительность МВИ - 25 мин. времени облучения. 
В работе [91] предложен способ выделения арабиногалактана из древесины лиственницы с использованием микроволнового излучения. Образец древесины заливают водой и обрабатывают МВИ мощностью 800 Вт в микроволновой печи в течение 1 мин. После обработки раствора (концентрирование, высаживание) выделяют арабиногалактан. Показано, что использование МВИ позволяет увеличить выход арабиногалактана до $25 \%$ (без МВИ выход составляет 13,3\%).

Микроволновое излучение использовано для получения пектина из кожуры маракуйи [92]. В качестве экстрагента использованы винная, уксусная и азотная кислоты. Были исследованы условия экстракции на выход пектина методом полного факторного эксперимента. Использование всех исследованных экстрагентов приводит к высоким выходам пектина.

В Китае произрастает и широко используется в медицинских целях растение Cyclocarya paliurus. Однако при этом образуется большое количество отходов, которые не находят квалифицированного применения. В работе [93] исследованы методы выделения из них полисахаридов. Для этой цели авторы использовали методы выделения с использованием традиционного нагрева, а также ультразвукового воздействия и микроволнового излучения. Показано, что использование микроволнового излучения позволяет значительно увеличить выход полисахаридов (до 5\%) и значительно сократить продолжительность процесса (20 мин), по сравнению с другими исследованными методами. С использованием полного факторного эксперимента были установлены оптимальные условия для максимального выхода полисахаридов. Однако авторы не уделяют внимания составу выделенных полисахаридов и их молекулярно-массовому распределению.

С использованием метода полного факторного эксперимента изучен процесс и подобраны оптимальные условия извлечения полисахаридов с помощью микроволнового излучения из плодов Lycium ruthenicum (дереза русская, «волчья ягода») и изучена их антиоксидантная активность [94]. Максимальный выход достигался в течение 25 мин при мощности МВИ 540 Вт. Состав полисахаридов в работе не приводится.

Методом полного факторного эксперимента изучено выделение лигнина из соломы тритикале ${ }^{*}$ экстракцией этанолом в присутствии серной кислоты под воздействием микроволнового излучения [95]. Максимальный выход лигнина составил 91\% (от общего лигнина). Установлены условия (температура, содержание этанола, концентрация серной кислоты), которые приводят к получению лигнина с максимальным выходом. Использование МВИ приводит к более высокому выходу лигнина, по сравнению с традиционным нагревом. Причем лигнин, полученный с использованием МВИ, характеризуется небольшим содержанием связанных углеводов и более низкой молекулярной массой. Анализ состава и химического строения лигнинов, полученных при традиционном нагреве и с использованием МВИ, показал их практически полное сходство. Полученные данные демонстрируют потенциальную применимость МВИ для получения лигнинов высокой чистоты и с низкой молекулярной массой, которые могут быть использованы в качестве макромономеров в производстве различных материалов (например, смола, пена). Аналогичные исследования проведены по изучению выделения лигнинов с использованием микроволнового излучения из соломы других травянистых растений - пшеница, кукуруза, лен, конопля [96].

Различные ионные жидкости широко могут быть использованы для избирательного растворения отдельных компонентов из растительной биомассы [97]. Известны работы, в которых описано использование ИЖ для растворения целлюлозы [98]. В обзоре [99] рассмотрен целый ряд ИЖ, которые с успехом могут быть использованы в качестве растворяющих систем и для отдельных высокомолекулярных структурных компонентов, и в целом всей биомассы древесины. Отмечается, что использование МВИ может значительно ускорить полноту и продолжительность процесса растворения. Описаны несколько методов фракционирования, которые позволяют разделить древесину на отдельные компоненты - целлюлозу, лигнин, гемицеллюлозы. Кроме того использование ИЖ открывает широкие перспективы по использованию полученных растворов при дальнейшем гомогенном химическом модифицировании.

\section{Суика растительной биомассы}

Применение микроволнового излучения для сушки различных растительных объектов, в том числе и пищевого назначения, известно достаточно давно и хорошо освещено в литературе [100].

Исследовано влияние различных способов сушки (на солнце, традиционный нагрев и микроволновое излучение) на содержание отдельных компонентов в Stevia rebaudiana Bertoni [101]. Изучено содержание влаги, золы, белка, жира, углеводов, пищевых волокон и некоторых тяжелых металлов. Установлено, что содержание исследованных компонентов практически не зависит от способа высушивания, однако при использовани МВИ содержание углеводов, танина несколько выше.

\footnotetext{
* Тритикале - гибрид пшеницы и ржи
} 
Изучено влияние различных видов сушки на содержание полифенолов и флавоноидов [102] в шалфее лекарственном (Salvia officinalis L.), а также на химических состав эфирного масла и его антиоксидантную активность [103]. Было показано, что использование микроволновой сушки приводит к увеличению массовой доли полифенолов в 4,2 раза по сравнению со свежим растением. Инфракрасная и конвекционная сушка приводят к общему их снижению. Полученные результаты свидетельствуют о том, что использование микроволнового излучения позволяет сохранить фенольные соединения при высушивания лекарственных растений. Состав эфирного масла сильно зависит от способа высушивания. Концентрация основных компонентов (1,8-цинеол, $\alpha$ - и $\beta$-туйон, камфара и др.) максимальна при высушивании на воздухе. В то же время установлено, что антиоксидантная активность наибольшая у масла, полученного с использованием микроволновой сушки.

Эфирное масло, выделенное методом гидродистилляции из базилика, подвергали высушиванию различными способами (на солнце, в тени, в сушильном шкафу при 40 и $60{ }^{\circ} \mathrm{C}$, в микроволновой печи при 500 Вт и вымораживанием) [104]. Установлено, что самые значительные изменения в составе эфирных масел (прежде всего потеря некоторых монотерпенов) наблюдаются при использовании сушильного шкафа и микроволновой печи.

Исследована возможность использования микроволновой сушки для выделения геномной ДНК на примере листьев Brosimum alicastrum [105]. Несмотря на то что микроволновая сушка может быть полезной альтернативной для подготовки образца к выделению из него ДНК, авторами работы установлено, что ее использование нежелательно, так как при этом снижается концентрация экстрагируемой геномной ДНК и, кроме того, экстракт ДНК содержит дополнительные примеси.

Микроволновое излучение предложено применять для сушки зерна пшеницы после его обработки водными растворами различных растворимых веществ (протравители, «прилипатели», стимуляторы, средства защиты и т.д.) [106]. Показано, что использование микроволнового излучения приводит к некоторому снижению жира, но улучшает физико-механические показатели - нанесенный слой тоньше, плотнее, гранулы получаются более устойчивыми, неслипшимися и обладают большей «текучестью».

В статье [107] подробно обсуждаются физические процессы, протекающие при сушке древесины. Отдельно рассматривается роль воды в процессе преобразования электромагнитного излучения в тепло. Отмечены преимущества микроволновой сушки по сравнению с традиционным нагревом.

При сравнении влияния на прочность древесины микроволнового и традиционного (конвекционного) способа сушки отмечается, что сам метод сушки не влияет на эксплуатационные свойства древесины [108]. На прочность оказывают воздействие такие факторы, как содержание влаги, возраст, плотность древесины.

В промышленных масштабах МВИ встречается при проведении сушки древесины [109, 110]. В частности в работе [111] описан пример реализации в промышленном масштабе технологии модифицирования древесины с использованием микроволнового излучения. Данная технология основана на использовании высокой мощности МВИ (до 135 кВт/м ${ }^{3}$ ) на частотах 0,922 и 2,45 ГГц. Такое сильное воздействие вызывает значительные изменения в микроструктуре древесины и резкое увеличение проницаемости древесины. Оно позволяет проводить обработку твердых пород древесины консервантами, быструю сушку древесины, модифицирование щепы для варки целлюлозы и др. Были разработаны технологии и сконструировано оборудование, готовые для коммерческого использования. Использование данных предложений в промышленном масштабе обеспечивает значительную экономию материальных ресурсов и энергии, что позволяет рекомендовать их для широкого использования в целлюлозно-бумажной промышленности и других областях переработки древесины.

\section{Разложение (пиролиз)}

В обзоре [112] дан критический анализ использования различных методов обработки древесины для получения из нее полезных веществ, и прежде всего для нужд энергетики. Одним из способов проведения термического разложения биомассы растений, которому в последнее время уделяют много внимания, является микроволновое излучение. В цитируемом обзоре представлен анализ последних публикаций, посвященных применению МВИ для получения из биомассы растений и их отходов биотоплива, и в частности синтез-газа $\left(\mathrm{CO}+\mathrm{H}_{2}\right)$. Отмечается, что использование МВИ более выгодный процесс по сравнению с традиционным пиролизом с энергетической точки зрения и по выходу синтез-газа.

В работе [113] исследован процесс быстрого пиролиза древесины под воздействием микроволнового излучения. Пиролизу подвергались цилиндрические деревянные блоки (диаметр 60-300 мм, вес 8012000 г) в специализированных микроволновых печах мощностью 1,5 и 3 кВт. Пиролиз древесины может быть выполнен в течение 15 мин для древесных блоков диаметром 100 мм. Было показано, что распреде- 
ление температуры внутри древесного блока, теплообмен и массообмен сильно отличаются от обычного способа нагрева. Были получены математические зависимости, связывающие размер древесных блоков с эффективностью процесса пиролиза и энергопотреблением. Удельная поверхность полукокса, полученного с использованием МВИ, больше, чем при традиционном нагреве. Выход смолы составил 15-30\%; содержание левоглюкозана в смоле - 5-9\%.

Проведено термическое модифицирование торфа под воздействием микроволнового излучения с целью получения из него гидрофобного сорбента [114]. Авторами изучено влияние продолжительности и мощности микроволновой обработки на сорбционную емкость. Полученный продукт обладает высокими сорбционными показателями по отношению к нефти.

Микроволновое излучение с успехом можно применять для получения активированного угля [115, 116]. Показано [116], что воздействием МВИ на рисовую шелуху, предварительно пропитанную КОН в течение 3-5 мин, можно получить углеродистые материалы, обладающие высокой удельной поверхностью (до 1505 м²/г).

Процессы пиролиза в микроволновых печах традиционно используют для полного разложения растительной биомассы в присутствии неорганических кислот, с целью последующего элементного анализа, прежде всего для определения различных микроэлементов [117-119].

\section{Гидролиз, делигнификация}

Различные примеры гидролиза растительной биомассы и разнообразных растительных отходов с целью получения из них биотоплива (биоэтанол) подробно рассмотрены в обзоре [112]. Отмечается высокая эффективность применения МВИ, которое способствует быстрому разрушению растительной клетки и, на первом этапе, эффективному разделению высокомолекулярных структурных компонентов углеводной и ароматической природы и в дальнейшем гидролизу полисахаридов до глюкозы.

В работе [120] изучается процесс делигнификации рисовой соломы с целью последующей переработки для получения биотоплива. Исследовано влияние условий микроволнового излучения на свойства продуктов после обработки рисовой соломы пероксидом водорода. Показано, что минимальное содержание лигнина и максимальное количество восстанавливающих углеводов было получено при обработке $\mathrm{H}_{2} \mathrm{O}_{2}(2 \%)$ при мощности микроволнового излучения 100 Вт в течение 3 мин. Аналогичное исследование поведено для делигнификации древесины бука, но в присутствии молибдата аммония [121].

Также для достижения максимального выхода моносахаридов при ферментативном гидролизе лигноцеллюлозы были изучены условия предварительной щелочной обработки ячменной соломы под воздействием микроволнового излучения [122]. Найдены мощность и продолжительность микроволнового излучения, концентрация щелочи, которые позволяют получить максимальное содержание в растворе сахаров.

Аналогичные исследования были проведены ранее [123], при варке отходов растениеводства (рисовая солома, отходы биомассы бананов и кукурузных початков) с использованием различных методов, и в том числе микроволнового излучения. Затем углеводную часть перерабатывали с помощью ферментативного гидролиз и последующего получения из глюкозы этанола. В работе [124] исследован кислотный гидролиз целлюлоз до глюкозы под воздействием микроволнового излучения с последующей ее переработкой в этанол. Показано, что использование МВИ позволяет сократить продолжительность процесса в 3-4 раза по сравнению с традиционным нагревом. Аналогичное исследование проведено на примере кислотного гидролиза отходов после получения пальмового масла [125].

Изучено влияние микроволнового излучения на свойства древесины сосны, обработанной разбавленным раствором серной кислоты (0,2-5\%) (гидромодуль $1: 10)$ [126]. Установлено, что МВИ оказывает значительное влияние на все компоненты клеточной стенки, что доказывается химическим анализом, УФи ИК-спектроскопическими исследованиями. Обработка древесины сосны МВИ приводит к увеличению относительного содержания целлюлозы (до 5-8\%) и лигнина (до 5-6\%), а легкогидролизуемых и трудногидролизуемых полисахаридов - уменьшается на 5-16\% и 5-14\% соответственно, что объясняется гидролизом гемицеллюлоз в процессе обработки. Результаты контрольных опытов показывают, что с увеличением мощности и продолжительности МВИ гидролиз гемицелюлоз происходит более интенсивно.

С целью разрушения растительной клетки твердой косточки сливы (Prunus Mume) ее подвергали автогидролизу в закрытом сосуде при температурах $110-230{ }^{\circ} \mathrm{C}$ и давлении до 5,5 МПа под воздействием микроволнового излучения [127]. Найдены условия, при которых из полученной массы могут быть выделены углеводы (полученные при разрушении гемицеллюлоз), целлюлоза, а также фенольные соединения (экстрактивные вещества и фрагменты разрушенного лигнина). 


\section{Химическое модифицирование биополимеров растительного происхождения}

Полисахариды являются одним из наиболее популярных возобновляемых природных полимеров, которые достаточно широко используются в различных областях жизнедеятельности человека. Это связано не только с их уникальными физико-химическим свойствами, которые позволяют получать из них большое число товарных продуктов, но и с возможностью их разнообразного химического модифицирования, которое дает значительный потенциал для дальнейшего поиска новых полезных продуктов и материалов на их основе. Однако традиционные способы химического модифицирования полисахаридов сталкиваются с рядом проблем: это и их деполимеризация при проведении химических реакций; необходимость инертной среды (растворителя); параллельные конкурирующие реакции, которые снижают выход продукта. В обзоpax [87, 128] приведены примеры химического модифицирования полисахаридов с применением микроволнового излучения, которое позволяет не только решить большинство из вышеперечисленных проблем, но и осуществить такие реакции, которые трудно проходят в обычных условиях. Также отмечается значительное их ускорение и снижение энергетических затрат.

Для повышения водоудерживающей способности целлюлозы был исследован процесс обработки целлюлозы сшивающими реагентами (сополимер метилвинилового эфира и малеиновой кислоты и полиэтиленгликоль) [129]. Проведено сравнение традиционного и микроволнового способов нагрева для сшивания целлюлозы. Были найдены условия для микроволнового (105 с при 1600 Вт) и традиционного нагрева $\left(130{ }^{\circ} \mathrm{C}\right.$ в течение 6,5 мин), обеспечивающие максимальное водоудерживание. Оба метода позволяют успешно получать новые сверхабсорбирующие волокна. Использование микроволнового излучения позволяет получать абсорбенты, позволяющие удерживать 45-413\% по сравнению с контролем, а традиционный нагрев $210-582 \%$. Авторы делают вывод, что использование микроволновой энергии позволяет получать продукты с высокой водоудерживающей способностью, при этом значительно сокращается продолжительность реакции.

Микроволновое излучение было использовано на стадии отбелки древесной целлюлозы [130]. В работе приведены результаты, которые свидетельствуют о высокой эффективности использования микроволновой энергии для проведения процесса отбеливания целлюлозы. Но при этом авторы отмечают неравномерность нагрева, что может привести к некачественной отбелке. Необходимо использование эффективного перемешивания. С осторожностью следует подходить к применению МВИ для тепловой обработки светочувствительных материалов, поскольку это может привести к разрушению материала, особенно в случае, когда в нем присутствует химически связанная вода.

В работе [131] изучено влияние микроволнового излучения на пероксидную отбелку целлюлозы из соломы пшеницы. Было показано, что наилучшие результаты получены при проведении процесса в течение 60 с при мощности МВИ 462 Вт. При сравнение с традиционным способом проведения пероксидной отбелки отмечено, что при использовании МВИ превращения остаточного лигнина происходят более глубоко и белизна полученной целлюлозы выше.

В работе [132] изучена реакция этерификации целлюлозы из Posidonia oceanica* янтарным, малеиновым и фталевым циклическими ангидридами. Предварительно выделенную из Posidonia oceanica целлюлозу сначала растворяли в системе $\mathrm{LiCl} / \mathrm{N}, \mathrm{N}$-диметилацетамид, а затем этерифицировали ангидридом в присутствии катализаторов (N,N-диметил-4-аминопиридин, трипропиламин, трибутиламин) под воздействием микроволнового излучения. Таким образом, продолжительность реакции была сокращена от нескольких часов до нескольких минут. В продуктах определялось содержание сложноэфирных групп и ис-

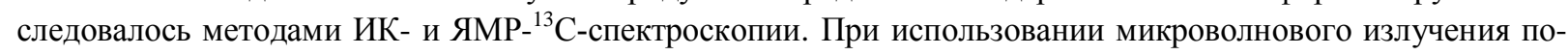
лучены продукты со степенью замещения (С3) 2,25 в течение 10 мин, в то время как при традиционном нагреве С3, равная 1,2, достигается за 12 ч.

Впервые были получены сшитые сложные эфиры целлюлозы при воздействии на раствор целлюлозы в системе $\mathrm{LiCl}$ /диметилацетамид (ДМАА) 10-ундецеонил хлорида под воздействием микроволнового излучения [133]. Продолжительность процесса ацилирования при мощности МВИ 800 Вт составляла от 1,5 до 4 мин. При этом максимальная степень замещения достигала 2.

Авторами [134] было обнаружено, что целлюлоза, активированная щелочью, может реагировать с хлоруксусной кислотой при действии МВИ с образованием КМЦ, обладающей различными характеристиками, за короткое время без деполимеризации целлюлозы электромагнитным излучением. Для этого

\footnotetext{
*Posidonia oceanica - вид морских травянистых растений (так называемых «морских трав»), распространен вдоль побережья Средиземного моря и близлежащих частей Атлантического океана. Используется в качестве упаковочного материала, для покрытия крыш, а также из листьев получают волокно для изготовления грубых тканей.
} 
целлюлозу диспергировали в растворе карбоксиметилирующих агентов и обрабатывали МВИ с частотой 0,01-23 ГГц, после чего отделяли образовавшуюся КМЦ. Продолжительность обработки в электромагнитном поле изменяли от 1 до 120 мин, предпочтителен интервал от 1 до 60 мин.

Было проведено карбоксиметилирование стеблей хлопка с целью получения карбоксиметилцеллюлозы с использованием МВИ [135]. Найдены оптимальные условия проведения реакции. Процесс включает стадию выделения целлюлозы из стеблей хлопка обработкой $12 \%$-м раствором $\mathrm{NaOH}$ в течение 6 мин при мощности МВИ 200 Вт (выход целлюлозы 87,5\%). Далее процесс карбоксиметилирования исследовали методом полного факторного эксперимента. Установлено, что оптимальными условиями проведения процесса карбоксиметилирования, приводящим к получению карбоксиметилцеллюлозы со С3 0,77, являются: массовое соотношение реагентов - целлюлоза : (гидроксид натрия) : (монохлорацетат натрия) = 1,0 : 1,1 : 1,2, мощность МВИ - 200 Вт; общая продолжительность процесса - 1,97 мин.

Разработан быстрый и эффективный способ получения карбоксиметиловых эфиров гемицеллюлоз с использованием микроволнового излучения [136]. Изучены основные условия проведения реакции и их влияние на степень замещения продуктов. Исследование реологических свойств растворов гемицеллюлоз показало, что полученные растворы имеют более низкие вязкости по сравнению с растворами исходных гемицелюлоз, что связано со снижением молекулярных масс при проведении карбоксиметилирования.

Изучено влияние ультразвукового и микроволнового (синергического) воздействия при карбоксиметилировании крахмала из маниоки [137]. Оптимизированы условия проведения реакции и исследованы свойства карбоксиметилпроизводных. Степень замещения в полученных продуктах изменяется от 0,4 до 1,1. Получены продукты с высокой степенью замещения. Аналогичная работа проведена с крахмалом, полученным из саго [138]. Максимально достигнутая степень замещения - 0,31.

Описан способ получения карбаматов целлюлозы с использованием микроволнового излучения из целлюлозы и мочевины без растворителя и катализатора [139]. Состав продуктов охарактеризован химическим анализом и методами ИК-Фурье-, ЯМР ${ }^{13} \mathrm{C}$ спектроскопии (FT-IR), рентгенодифрактометрии, сканирующей электронной микроскопии и термогравиметрии.

\section{Химическое модифицирование растительного сырья}

Химическое модифицирование растительного сырья без предварительного разделения на отдельные компоненты привлекает многих исследователей по всему миру, так как это открывает широкие перспективы по созданию большой номенклатуры новых материалов, которые могут найти широкое применение во многих отраслях науки и производства [140-143].

Одним из путей повышения эффективности химического модифицирования растительного сырья может быть использование микроволнового излучения как на стадии предварительной активации и подготовки сырья, так и при химическом взаимодействии. Известно несколько химических реакций, которые приводят к получению ценных продуктов и материалов. Среди них следует указать прежде всего реакции, приводящие к образованию простых и сложных эфиров.

Ацилирование древесины известно достаточно давно и получило промышленное использование. Так, ацетилирование древесных блоков (досок, брусков, бревен и других изделий) приводит к более длительному использованию изделий и сохранению у них первоначального вида, способствует сохранению размеров и устойчивости к грибковым заболеваниям. Обычно процедура ацетилирования состоит из начальной пропитки уксусным ангидридом, после чего избыток ангидрида стекает и пропитанную древесину подвергают нагреванию при 120-130 ㄷ․ В серии работ, посвященных исследованию ацетилирования древесных блоков уксусным ангидридом [144, 145], использовано микроволновое излучение. Авторами показано, что микроволновая энергия эффективно способствует нагреванию уксусного ангидрида и проникновению его внутрь древесного блока. Установлены диэлектрическая проницаемость древесины и древесины, обработанной уксусным ангидридом, а также глубина его проникновения в древесный блок. В работе [146] изучена возможность удаления избытка уксусного ангидрида с использованием микроволнового излучения после ацетилирования древесных блоков.

Одним из наиболее исследованных процессов является карбоксиметилирование древесины (и другого растительного сырья) монохлоруксусной кислотой суспензионным [147-150] или твердофазным способами [151-154]. При этом в реакцию вступают ОН-группы всех основных структурных компонентов исходного сырья (целлюлоза, лигнин, гемицеллюлозы). Реакция как на стадии предварительной обработки $\mathrm{NaOH}$, так и при обработке монохлоруксусной кислотой (МХУК) или натриевой солью монохлоруксусной кислоты (Na-MХУК) ускоряется при повышении температуры. 
Впервые карбоксиметилирование древесины под воздействием микроволнового излучения предложено в работах [155-158]. Законченное исследование влияния микроволнового излучения на протекание реакции карбоксиметилирования растительного сырья было проведено в работе М.Ю. Чепрасовой [159]. Было показано, что реакцию карбоксиметилирования различных видов растительного сырья можно осуществить под воздействием микроволнового излучения, как на стадиях обработки $\mathrm{NaOH}$ и/или монохлоацетатом натрия, так и при одновременной загрузке $\mathrm{NaOH}$ и $\mathrm{Na-MХУК}[155,156]$. При этом образуются продукты, которые в своем составе содержат сходное количество карбоксиметильных групп (КМГ), что и продукты полученные суспензионным методом. Следует отметить, что общая продолжительность процесса при проведении карбоксиметилирования суспензионным способом составляет 3-4 ч, а при использовании микроволнового излучения - до 2 мин.

В работе $[157,160]$ изучено влияние различных растворителей на процесс реакции карбоксиметилирования древесины осины под воздействием микроволнового излучения. При этом получены продукты, содержащие в своем составе от 4,6 до 25,9\% карбоксиметильных групп. Показано, что использование микроволнового излучения позволяет сократить общую продолжительность процесса карбоксиметилирования до 200 раз. В результате анализа свойств продуктов карбоксиметилирования древесины осины установлено, что из карбоксиметилированной древесины, полученной с использованием микроволнового излучения, можно выделить карбоксиметилцеллюлозу (КМЦ) с более высоким выходом и с большей долей карбоксиметильных групп в ней, чем при традиционном нагреве. Это свидетельствует об интенсивных деструкционных процессах, протекающих при термическом нагреве, что приводит к снижению выхода КМЦ почти в 2 раза. Содержание карбоксиметильных групп в КМЦ, полученной как при использовании МВИ, так и при термическом нагреве, сравнимо. Доля КМГ, приходящихся на КМЦ, от общего количества КМГ в карбоксиметилированной древесине при традиционном нагреве изменяется от 6 до 16\%, а при использовании МВИ - от 14 до 51\%. Таким образом, при использовании микроволнового излучения практически уравнивается реакционная способность ОН-групп всех основных структурных компонентов древесины, а при использовании термического нагрева, как это и было показано ранее [161], процесс карбоксиметилирования, главным образом, зависит от диффузионных процессов доставки реагентов к реакционным центрам. Лучшей реакционной средой (с точки зрения общего содержания КМГ) является вода.

Исследование молекулярно-массового распределения карбоксиметилцеллюлозы, выделенной из карбоксиметилированной древесины, полученной при использовании микроволнового излучения в среде различных растворителей, показывает, что реакционная среда оказывает существенное влияние на молекулярно-массовые характеристики КМЦ [162]. Деструкция карбоксиметилцеллюлозы, выделенной из карбоксиметилированной древесины, полученной в среде различных растворителей при воздействии микроволнового излучения, меньше, чем при суспензионном способе карбоксиметилирования древесины.

Изучена [163, 164] реакция карбоксиметилирования древесины сосны, подвергнутой предварительной обработке в смеси «уксусная кислота - пероксид водорода - вода - катализатор». Данная предварительная обработка проводилась с целью повышения доступности ОН-групп всех основных компонентов древесины и, как следствие, повышения эффективности последующего карбоксиметилирования. Установлено, что продолжительность и мощность микроволнового излучения незначительно влияют на выход и состав древесины сосны при использовании в качестве катализатора серной кислоты. Применение молибдата аммония приводит к снижению выхода твердого остатка (до 56-72\%) и более интенсивному окислению лигнина. В результате карбоксиметилирования древесины сосны после ее предварительной обработки в смеси «уксусная кислота - пероксид водорода - вода - катализатор» под воздействием микроволнового излучения получены высокозамещенные продукты с содержанием КМГ 17-29\%. Использование на стадии предварительной обработки в качестве катализатора молибдата аммония приводит к получению карбоксиметилированной древесины сосны с более низкой растворимостью в воде (19-32\%), по сравнению с серной кислотой (92-94\%). Степень полимеризации карбоксиметилцеллюлозы, выделенной из карбоксиметилированой древесины сосны, остается на достаточно высоком уровне и изменяется в пределах от 580 до 880 в зависимости от условий предварительной обработки в смеси «уксусная кислота - пероксид водорода - вода - катализатор».

С целью получения карбоксиметилированной древесины сосны в виде калиевой соли проведена обработка древесины сосны гидроксидом калия и монохлоруксусной кислотой в среде пропанола-2 под воздействием микроволнового излучения $[165,166]$. Из карбоксиметилированной древесины сосны выделена карбоксиметилированная целлюлоза. Установлено, что увеличение мощности микроволнового излучения (от 210 до 700 Вт) и продолжительности первой и второй стадий процесса карбоксиметилирования (20-30 c) приводит к повышению содержания карбоксиметильных групп (18,3-25,6\%). Обнаружена аномально низ- 
кая растворимость калиевых солей карбоксиметилированной древесины сосны (10-18\%) по сравнению с натриевыми солями при сравнимом содержании карбоксиметильных групп. Проведено исследование вязкости водных растворов карбоксиметилированной древесины сосны и карбоксиметилированной целлюлозы, выделенной из нее. Показано, что образцы, полученные при мощности микроволнового излучения 210 Вт, обладают аномальными кривыми течения.

В работах $[167,168]$ обобщено влияние микроволнового излучения на процесс карбоксиметилирования растительного сырья без его предварительного разделения на отдельные компоненты. Делается вывод о том, что микроволновое излучение значительно сокращает продолжительность процесса (до 200 раз) по сравнению с суспензионным способом карбоксиметилирования. При этом содержание карбоксиметильных групп в составе продукта не ниже, а часто и выше, чем при использовании традиционного нагрева. Поведение отдельных структурных компонентов в составе растительного сырья также отличается при проведении процесса карбоксиметилирования с использованием МВИ. Установлено, что структурные компоненты (целлюлоза, лигнин) менее избирательно взаимодействуют с монохлорацетатом натрия при использованиии МВИ. Молекулярно-массовое распределение карбоксиметилцеллюлозы, выделенной из карбоксиметилированного растительного сырья, сильно зависит от реакционной среды, использованной для проведения реакции. Но в целом использование микроволнового излучения при карбоксиметилировании растительного сырья приводит к повышению доли высокомолекулярной фракции карбоксиметилированной целлюлозы, выделенной из карбоксиметилированного растительного сырья.

Таким образом, использование микроволнового излучения для химического модифицирования растительного сырья, и прежде всего древесины, без предварительного разделения на отдельные компоненты открывает новые возможности перед учеными по созданию новых технологий, позволяющих быстро осуществлять эффективное модифицирование высокомолекулярных компонентов растительной клетки с целью получения новых продуктов и материалов.

\section{Другие процессы}

В работе [169] разработан «зеленый» способ получения алюминийсодержащих наночастиц из нитрата алюминия с использованием экстрактов чая, кофе и других растений под воздействием микроволнового излучения. Синтез осуществляют при соотношении соли алюминия и экстракта $1: 4$ при мощности МВИ 540 Вт при использовании воды в качестве растворителя. Синтезированные наночастицы охарактеризованы с помощью методов сканирующей электронной микроскопии, УФ- и ИК-Фурье-спектроскопии. В результате исследований разработан легкий, отвечающий принципам «зеленой химии» подход к использованию растительных экстрактов в качестве восстановителя для синтеза наночастиц определенного размера, который не требует применения токсичных химических веществ. Формирование наночастиц под воздействием МВИ с использованием растительных экстрактов оказалось быстрее, чем любой другой известный метод. Данный способ может найти применение в будущем, особенно для биомедицинских целей.

Похожий способ получения наночастиц золота в присутствии экстракта Cissus quadrangularis c использованием МВИ предложен в работе [170].

Проведено сравнение традиционного способа нагрева и влияния микроволнового излучения на термическое растворение (ожижение) древесины в глицерине и полиэтиленгликоле (ПЭГ 400) [171]. По сравнению с традиционным нагревом использование МВИ позволяет быстро (2 мин) провести ожижение древесины в присутствии ПЭГ 400 / глицерина. Найдены условия для наиболее эффективного проведения процесса (продолжительность, температура, соотношение растворитель / древесина, влажность древесины, концентрация серной кислоты, как катализатора). Полученные на основе биомассы древесины полиолы могут быть использованы для получения пенополиуретанов.

\section{Микроволновье эффекты}

С момента использования микроволнового излучения для проведения химических взаимодействий в литературе происходит активная дискуссия о причинах столь резкого ускорения реакций. Ускорение связано только лишь с термическим нагревом по всему объему реакционной смеси, или все-таки существует «специфический микроволновой эффект», оказывающий непосредственное воздействие на реагирующие молекулы (повышает энергию активации), что приводит к резкому ускорению химической реакции? Одинаковы ли механизмы химических превращений, протекающих под воздействием микроволнового излучения и при традиционном нагреве?

Анализ работ, приведенных в настоящем обзоре, свидетельствует о том, что исследователи главным образом описывают примеры, условия использования МВИ, свойства получаемых соединений, но не объяс- 
нения влияния микроволнового излучения на вещество. Лишь в некоторых работах предпринимается попытка объяснения природы влияния МВИ на вещество и предлагаются модели этого взаимодействия. Так, в работе [51] предлагается математическая модель, которая описывает изменение температуры, концентрации экстракта во время непрерывного и прерывистого воздействия микроволновой энергией при выделении $\beta$-каротина из моркови. Модель была экспериментально подтверждена и способна вполне адекватно предсказывать изменение температуры и концентрации $\beta$-каротина. В обзоре [172] обсуждены теории, лежащие в основе микроволнового диэлектрического нагрева и представлены диэлектрические данные для широкого круга органических растворителей, которые широко используются для микроволнового синтеза.

Большинство исследователей склоняется к точке зрения, что в основе ускорения лежит большая частота соударений реагирующих молекул, что вызывает быстрый объемный разогрев вещества. Но ряд ученых считают, что существует «микроволновой эффект», так как полученные кинетические данные не укладываются в рамки модели объемного теплового эффекта. Поэтому, несмотря на большое количество работ, посвященных данной проблеме, ответ на это вопрос остается открытым и, очевидно, требует дополнительных исследований.

\section{Заключение}

Результаты исследований в микроволновой химии показали высокую эффективность и возможности применения микроволнового излучения в качестве источника энергии для проведения многих процессов при переработке растительного сырья. Настоящий обзор наглядно иллюстрирует современное состояние научных исследований в данной области. Практически во всех основных сферах переработки растительного сырья показана эффективность использования микроволнового излучения. Несмотря на то, что работы в данной области начаты сравнительно недавно, к настоящему времени достигнуты значительные успехи. К сожалению, эти исследования пока не получили должного распространения в промышленных технологиях. Некоторые положительные примеры использования промышленных микроволновых установок описаны в работах [109-111, 173].

Таким образом, интерес к исследованиям использования микроволнового излучения в процессах переработки растительного сырья будет только возрастать, так как перед исследователями и производственниками открываются весьма заманчивые перспективы получения разнообразных продуктов и материалов с высокой скоростью и с минимальными затратами энергии.

\section{Список литературы}

1. Sheldon R.A. Fundamentals of green chemistry: Efficiency in reaction design // Chemical Society Reviews. 2012. V. 41, N4. Pp. 1437-1451.

2. Höfer R., Bigorra J. Biomass-based green chemistry: Sustainable solutions for modern economies // Green Chemistry Letters and Reviews. 2008. V. 1, N2. Pp. 79-97.

3. Michael D., Mingos P., Baghurst D.R. Applications of microwave dielectirc heating effects to synthetic problems in chemistry // Chemical Society Reviews. 1991. V. 20, N1. Pp. 1-47.

4. Metaxas A.C., Meredith R.J. Industrial Microwave Heating. London, P. Peregrinus. 1983. Vol. 1. 357 p.

5. Kingston H.M., Jassie L.B. Introduction to Microwave Sample Preparation: Theory and Practice. Washington, ASC. 1988. $263 \mathrm{p}$.

6. Strauss C.R., Trainor R.W. Developments in Microwave-Assisted Organic Chemistry // Australian Journal of Chemistry. 1995. V. 48, N10. Pp. 1665-1692.

7. Рахманкулов Д.Л., Бикбулатов И.Х., Шулаев Н.С., Шавтукова С.Ю. Микроволновое излучение и интенсификация химических процессов. М., 2003. 220 с.

8. Meredith R.J. Engineers Handbook of Industrial Microwave Heating. The Institution of Engineering and Technology, London, 1998. $377 \mathrm{p}$.

9. Ishii T.K. Handbook of Microwave Technology, Volume 1: Components and Devices. San-Diego, Academic Press, 1995.

10. Ishii T.K. Handbook of Microwave Technology. Volume 2, Applications. San-Diego, Academic Press, 1995.

11. Datta A.K. Handbook of Microwave Technology for Food Application (Food Science and Technology). NY, Marcel Drekker AG. 2001. 536 p.

12. Fernández Y., Arenillas A., Menéndez J.Á. Advances in induction and microwave heating of mineral and organic materials. Intech, 2011. $766 \mathrm{p}$.

13. Chandra U. Microwave Heating. Intech, 2011. 382 p.

14. The Development and Application of Microwave Heating. Intech, 2012. 222 p.

15. Sanghi R., Singh V. Green Chemistry for Environmental Remediation. CRC Press, 2012. 790 p.

16. Paré J.R.J., Bélanger J.M.R., Stafford S.S. Microwave-assisted process (MAPTM)a: A new tool for the analytical laboratory // TrAC - Trends in Analytical Chemistry. 1994. V. 13, N4. Pp. 176-184.

17. Microwave-Enhanced Chemistry. Fundamentals, Sample Preparation and Applications. Washington, ACS. 1997. 772 p.

18. Кубракова И.В. Микроволновое излучение в аналитической химии: возможности и перспективы использования // Успехи химии. 2002. Т. 71, №4. С. 327-340. 
19. Кубракова И.В., Мясоедова Г.В., Еремин С.А., Плетнев И.В., Моходоева О.Б., Морозова В.А., Хачатрян К.С. Подготовка проб в условиях микроволнового нагрева // Методы и объекты химического анализа. 2006. Т. 1, №1. С. $27-34$.

20. Camel V. Microwave-assisted solvent extraction of environmental samples // TrAC - Trends in Analytical Chemistry. 2000. V. 19, N4. Pp. 229-248.

21. Gedye R., Smith F., Westaway K., Ali H., Baldisera L., Laberge L., Rousell J. The use of microwave ovens for rapid organic synthesis // Tetrahedron Letters. 1986. V. 27, N3. Pp. 279-282.

22. Giguere R.J., Bray T.L., Duncan S.M., Majetich G. Application of commercial microwave ovens to organic synthesis // Tetrahedron Letters. 1986. V. 27, N41. Pp. 4945-4948.

23. Романова Н.Н., Гравис А.Г., Зык Н.В. Микроволновое облучение в органическом синтезе // Успехи химии. 2005. T. 74, №11. C. 1159-1105.

24. Lidström P., Tierney J., Wathey B., Westman J. Microwave assisted organic synthesis - A review // Tetrahedron. 2001. V. 57, N45. Pp. 9225-9283.

25. Kappe C.O., Stadler A. Microwaves in Organic and Medicinal Chemistry. Weinheim, Wiley-VCH. 2005. 422 p.

26. Kappe C.O., Dallinger D., Murphree S.S. Practical Microwave Synthesis for Organic Chemists. Weinheim, Wiley-VCH. 2009. $307 \mathrm{p}$.

27. Strauss C. Award for microwave chemistry // Green Chemistry. 1999. August. Pp. G94-G96.

28. Kappe C.O., Dallinger D. Controlled microwave heating in modern organic synthesis: Highlights from the 2004-2008 literature // Molecular Diversity. 2009. V. 13, N2. Pp. 71-193.

29. Mallakpour S., Rafiee Z. Application of microwave-assisted reactions in step-growth polymerization: A review // Iranian Polymer Journal (English Edition). 2008. V. 17, N12. Pp. 907-935.

30. Bogdal D., Prociak A. Microwave-enhanced polymer chemistry and technology. Blackwell Publishing Ltd, 2007. 284 p.

31. Chemat F., Cravotto G. Microwave-assisted Extraction for Bioactive Compounds. Theory and Practice. Springer US, 2013. $247 \mathrm{p}$.

32. Destandau E., Michel T., Elfakir C. Microwave-assisted extraction. Cambridge, 2013. Pp. 113-156.

33. Delazar A., Nahar L., Hamedeyazdan S., Sarker S. Microwave-Assisted Extraction in Natural Products Isolation // Natural Products Isolation: S.D. Sarker and L. Nahar, eds. 2012. V. 864. Pp. 89-115.

34. Kokolakis A.K., Golfinopoulos S.K. Microwave-assisted techniques (MATs); a quick way to extract a fragrance: A review // Natural Product Communications. 2013. V. 8, N10. Pp. 1493-1504.

35. Chua L.S. A review on plant-based rutin extraction methods and its pharmacological activities // Journal of Ethnopharmacology. 2013. V. 150, N3. Pp. 805-817.

36. Das A.K., Mandal V., Mandal S.C. A brief understanding of process optimisation in microwave-assisted extraction of botanical materials: Options and opportunities with chemometric tools // Phytochemical Analysis. 2014. V. 25, N1. Pp. 1-12.

37. Mason T.J., Chemat F., Vinatoru M. The extraction of natural products using ultrasound or microwaves // Current Organic Chemistry. 2011. V. 15, N2. Pp. 237-247.

38. Mahibalan S., Sharma R., Vyas A., Basha S.A., Begum A.S. Assessment of extraction techniques for total phenolics and flavonoids from Annona muricata seeds // Journal of the Indian Chemical Society. 2013. V. 90, N12. Pp. 2199-2205.

39. Delgado-Torre M.P., Ferreiro-Vera C., Priego-Capote F., Pérez-Juan P.M., Luque De Castro M.D. Comparison of accelerated methods for the extraction of phenolic compounds from different vine-shoot cultivars // Journal of Agricultural and Food Chemistry. 2012. V. 60, N12. Pp. 3051-3060.

40. Karabegović I.T., Stojičević S.S., Veličković D.T., Todorović Z.B., Nikolić N.T., Lazić M.L. The effect of different extraction techniques on the composition and antioxidant activity of cherry laurel (Prunus laurocerasus) leaf and fruit extracts // Industrial Crops and Products. 2014. V. 54, Pp. 142-148.

41. Xu W., Chu K., Li H., Zhang Y., Zheng H., Chen R., Chen L. Ionic liquid-based microwave-Assisted extraction of flavonoids from bauhinia championii (Benth.) benth // Molecules. 2012. V. 17, N12. Pp. 14323-14335.

42. Bai L.S., Yang Y., Lv D.D. Microwave extraction of total flavonoids in peanut skins $/ /$ Zhong yao cai = Zhongyaocai $=$ Journal of Chinese medicinal materials. 2012. V. 35, N6. Pp. 977-980.

43. Wataniyakul P., Pavasant P., Goto M., Shotipruk A. Microwave pretreatment of defatted rice bran for enhanced recovery of total phenolic compounds extracted by subcritical water // Bioresource Technology. 2012. V. 124, Pp. 18-22.

44. Yan Z., da-Yun S., Jing-Shu Z., Hong-Li Z. Microwave-assisted extraction and antihyperlipidemic effect of total flavonoids from corn silk // African Journal of Biotechnology. 2011. V. 10, N65. Pp. 14583-14586.

45. Zhang L., Wang Y., Wu D., Xu M., Chen J. Microwave-assisted extraction of polyphenols from camellia oleifera fruit hull // Molecules. 2011. V. 16, N6. Pp. 4428-4437.

46. Yang Y.C., Li J., Zu Y.G., Fu Y.J., Luo M., Wu N., Liu X.L. Optimisation of microwave-assisted enzymatic extraction of corilagin and geraniin from Geranium sibiricum Linne and evaluation of antioxidant activity // Food Chemistry. 2010. V. 122, N1. Pp. 373-380.

47. Zou T., Wu H., Li H., Jia Q., Song G. Comparison of microwave-assisted and conventional extraction of mangiferin from mango (Mangifera indica L.) leaves // Journal of Separation Science. 2013. V. 36, N20. Pp. 3457-3462.

48. Yan M.M., Liu W., Fu Y.J., Zu Y.G., Chen C.Y., Luo M. Optimisation of the microwave-assisted extraction process for four main astragalosides in Radix Astragali // Food Chemistry. 2010. V. 119, N4. Pp. 1663-1670.

49. Das A.K., Mandal V., Mandal S.C. Design of experiment approach for the process optimisation of microwave assisted extraction of lupeol from ficus racemosa leaves using response surface methodology // Phytochemical Analysis. 2013. V. 24, N3. Pp. 230-247.

50. Коптелова Е.Н., Кутакова Н.А., Третьяков С.И. Извлечение экстрактивных веществ и бетулина из бересты при воздействии СВЧ-поля // Химия растительного сырья. 2013. №4. С. 159-164. 
51. Chumnanpaisont N., Niamnuy C., Devahastin S. Mathematical model for continuous and intermittent microwave-assisted extraction of bioactive compound from plant material: Extraction of $\beta$-carotene from carrot peels // Chemical Engineering Science. 2014. V. 116, Pp. 442-451.

52. Boldor D., Kanitkar A., Terigar B.G., Leonardi C., Lima M., Breitenbeck G.A. Microwave assisted extraction of biodiesel feedstock from the seeds of invasive chinese tallow tree // Environmental Science and Technology. 2010. V. 44, N10. Pp. 4019-4025.

53. Ma C.H., Liu T.T., Yang L., Zu Y.G., Chen X., Zhang L., Zhang Y., Zhao C. Ionic liquid-based microwave-assisted extraction of essential oil and biphenyl cyclooctene lignans from Schisandra chinensis Baill fruits // Journal of Chromatography A. 2011. V. 1218, N48. Pp. 8573-8580.

54. Brodie G., Harris G., Jacob M.V., Sheehan M., Yin L. Microwave modification of sugar cane to enhance juice extraction during milling // Journal of Microwave Power and Electromagnetic Energy. 2011. V. 45, N4. Pp. 178-187.

55. Verma S.C., Jain C.L., Kumari A., Padhi M.M., Devalla R.B. Microwave-assisted extraction and rapid isolation of ursolic acid from the leaves of Eucalyptus $\times$ hybrida Maiden and its quantification using HPLC-diode array technique // Journal of Separation Science. 2013. V. 36, N7. Pp. 1255-1262.

56. Xia E.Q., Wang B.W., Xu X.R., Zhu L., Song Y., Li H.B. Microwave-assisted extraction of oleanolic acid and ursolic acid from Ligustrum lucidum ait // International Journal of Molecular Sciences. 2011. V. 12, N8. Pp. 5319-5329.

57. Puttarak P., Panichayupakaranant P. Factors affecting the content of pentacyclic triterpenes in Centella asiatica raw materials // Pharmaceutical Biology. 2012. V. 50, N12. Pp. 1508-1512.

58. Chen T., Sun X., Xiao W., Liu X., Zhang W., Ma K., Zhu Y. Optimization of microwave-assisted extraction of solanesol from potato leaves and stems // Medicinal Chemistry Research. 2010. V. 19, N8. Pp. 732-742.

59. Liu W., Zhou C.L., Zhao J., Chen D., Li Q.H. Optimized microwave-assisted extraction of 6-gingerol from Zingiber officinale roscoeand evaluation of antioxidant activity in vitro // Acta Scientiarum Polonorum, Technologia Alimentaria. 2014. V. 13, N2. Pp. 155-168.

60. Tang B., Bi W., Tian M., Row K.H. Application of ionic liquid for extraction and separation of bioactive compounds from plants // Journal of Chromatography B: Analytical Technologies in the Biomedical and Life Sciences. 2012. V. 904, Pp. 1-21.

61. Li X.J., Yu H.M., Gao C., Zu Y.G., Wang W., Luo M., Gu C.B., Zhao C.J., Fu Y.J. Application of ionic liquid-based surfactants in the microwave-assisted extraction for the determination of four main phloroglucinols from Dryopteris fragrans // Journal of Separation Science. 2012. V. 35, N24. Pp. 3600-3608.

62. Sun S., Zhai Y.J., Sun Y., Zhang Y.P., Liu H., Wang X.H., Yu A.M., Zhang H.Q. Application of ionic liquid-non polar solvent microwave extraction to the study of the chemical constituents from roots of Panax ginseng C.M. Mey // Gaodeng Xuexiao Huaxue Xuebao/Chemical Journal of Chinese Universities. 2010. V. 31, N3. Pp. 468-472.

63. Liu X., Wang Y., Kong J., Nie C., Lin X. Application of ionic liquids in the microwave-assisted extraction of quercetin from Chinese herbal medicine // Analytical Methods. 2012. V. 4, N4. Pp. 1012-1018.

64. Yuan Y., Wang Y., Xu R., Huang M., Zeng H. Application of ionic liquids in the microwave-assisted extraction of podophyllotoxin from Chinese herbal medicine // Analyst. 2011. V. 136, N11. Pp. 2294-2305.

65. Zeng H., Wang Y., Kong J., Nie C., Yuan Y. Ionic liquid-based microwave-assisted extraction of rutin from Chinese medicinal plants // Talanta. 2010. V. 83, N2. Pp. 582-590.

66. Gómez N.E., Witte L. A simple method to extract essential oils from tissue samples by using microwave radiation // Journal of Chemical Ecology. 2001. V. 27, N11. Pp. 2351-2359.

67. Chemat F., Perino-Issartier S., Petitcolas E., Fernandez X. «In situ» extraction of essential oils by use of Dean-Stark glassware and a Vigreux column inside a microwave oven: A procedure for teaching green analytical chemistry // Analytical and Bioanalytical Chemistry. 2012. V. 404, N3. Pp. 679-682.

68. Stashenko E.E., Jaramillo B.E., Martínez J.R. Comparison of different extraction methods for the analysis of volatile secondary metabolites of Lippia alba (Mill.) N.E. Brown, grown in Colombia, and evaluation of its in vitro antioxidant activity // Journal of Chromatography A. 2004. V. 1025, N1. Pp. 93-103.

69. Ferhat M.A., Tigrine-Kordjani N., Chemat S., Meklati B.Y., Chemat F. Rapid extraction of volatile compounds using a new simultaneous microwave distillation: Solvent extraction device // Chromatographia. 2007. V. 65, N3-4. Pp. 217-222.

70. Mircioaga N., Calinescu I. Extraction and identification of active principles from Mentha Piperita L. // Revista de Chimie. 2011. V. 62, N11. Pp. 1073-1076.

71. Jiang C., Sun Y., Zhu X., Gao Y., Wang L., Wang J., Wu L., Song D. Solvent-free microwave extraction coupled with headspace single-drop microextraction of essential oils from flower of Eugenia caryophyllata Thunb // Journal of Separation Science. 2010. V. 33, N17-18. Pp. 2784-2790.

72. Azar P., Porgham-Daryasari A., Saber-Tehrani M., Soleimani M. Analysis of the volatile compounds in Nepeta crispa willd. Using improved HS-SPME-GC-MS and comparison with conventional methods // Acta Chromatographica. 2012. V. 24, N1. Pp. 75-84.

73. Ma C.H., Yang L., Zu Y.G., Liu T.T. Optimization of conditions of solvent-free microwave extraction and study on antioxidant capacity of essential oil from Schisandra chinensis (Turcz.) Baill // Food Chemistry. 2012. V. 134, N4. Pp. 2532-2539.

74. Boukhari F., Tigrine-Kordjani N., Youcef Meklati B. Phytochemical investigation by microwave-assisted extraction of essential oil of the leaves of walnut cultivated in Algeria // Helvetica Chimica Acta. 2013. V. 96, N6. Pp. 1168-1175.

75. Li X.J., Wang W., Luo M., Li C.Y., Zu Y.G., Mu P.S., Fu Y.J. Solvent-free microwave extraction of essential oil from Dryopteris fragrans and evaluation of antioxidant activity // Food Chemistry. 2012. V. 133, N2. Pp. 437-444.

76. Azar P.A., Tehrani M.S., Hosain S.W., Khalilzadeh M.A., Zanousi M.B.P. Solvent-free microwave extraction of essential oil of artemisia tschernieviana // Asian Journal of Chemistry. 2012. V. 24, N11. Pp. 5388-5390. 
77. Uysal B., Sozmen F., Buyuktas B.S. Solvent-free microwave extraction of essential oils from Laurus nobilis and Melissa officinalis: Comparison with conventional hydro-distillation and ultrasound extraction // Natural Product Communications. 2010. V. 5, N1. Pp. 111-114.

78. Bajpai V.K., Sharma A., Kim S.H., Baek K.H. Phenolic content and antioxidant capacity of essential oil obtained from sawdust of Chamaecyparis obtusa by microwave-assisted hydrodistillation // Food Technology and Biotechnology. 2013. V. 51, N3. Pp. 360-369.

79. Orio L., Cravotto G., Binello A., Pignata G., Nicola S., Chemat F. Hydrodistillation and in situ microwave-generated hydrodistillation of fresh and dried mint leaves: A comparison study // Journal of the Science of Food and Agriculture. 2012. V. 92, N15. Pp. 3085-3090.

80. Gholivand M.B., Piryaei M., Abolghasemi M.M. Analysis of volatile oil composition of Citrus aurantium L. by microwave-assisted extraction coupled to headspace solid-phase microextraction with nanoporous based fibers // Journal of Separation Science. 2013. V. 36, N5. Pp. 872-877.

81. Benkaci-Ali F., Akloul R., Boukenouche A., Pauw E.D. Chemical Composition of the Essential Oil of Nigella sativa Seeds Extracted by Microwave Steam Distillation // Journal of Essential Oil-Bearing Plants. 2013. V. 16, N6. Pp. 781-794.

82. Périno-Issartier S., Abert-Vian M., Petitcolas E., Chemat F. Microwave turbo hydrodistillation for rapid extraction of the essential oil from Schinus terebinthifolius raddi berries // Chromatographia. 2010. V. 72, N3-4. Pp. 347-350.

83. Miletić P., Grujić R., Marjanović-Balaban Ž. The application of microwaves in essential oil hydrodistillation processes // Chemical Industry and Chemical Engineering Quarterly. 2009. V. 15, N1. Pp. 37-39.

84. Jiao J., Gai Q.Y., Fu Y.J., Zu Y.G., Luo M., Zhao C.J., Li C.Y. Microwave-assisted ionic liquids treatment followed by hydro-distillation for the efficient isolation of essential oil from Fructus forsythiae seed // Separation and Purification Technology. 2013. V. 107, Pp. 228-237.

85. Пунегов В.В., Костромин В.И., Фомина М.Г., Зайнуллин В.Г., Юшкова Е.А., Белых Д.В., Чукичева И.Ю., Зайнуллин Г.Г. Экстрагирование гиперицина и псевдогиперицина из зверобоя продырявленного в условиях микроволновой активации процесса // Химия растительного сырья. 2014. №1. С. 125-130.

86. Zhang G., Hu M., He L., Fu P., Wang L., Zhou J. Optimization of microwave-assisted enzymatic extraction of polyphenols from waste peanut shells and evaluation of its antioxidant and antibacterial activities in vitro // Food and Bioproducts Processing. 2013. V. 91, N2. Pp. 158-168.

87. Peng F., Peng P., Xu F., Sun R.C. Fractional purification and bioconversion of hemicelluloses // Biotechnology Advances. 2012. V. 30, N4. Pp. 879-903.

88. Tahmouzi S. Extraction, antioxidant and antilisterial activities of polysaccharides from the flower of viper's bugloss // International Journal of Biological Macromolecules. 2014. V. 69, Pp. 523-531.

89. Panthapulakkal S., Pakharenko V., Sain M. Microwave Assisted Short-Time Alkaline Extraction of Birch Xylan // Journal of Polymers and the Environment. 2013. V. 21, N4. Pp. 917-929.

90. Panthapulakkal S., Sain M. Optimization of Microwave Assisted Alkaline Extraction of Xylan from Birch Wood Using Response Surface Methodology // Chemistry \& Materials Science. 2013. V. 1, N6. Pp. 38-55.

91. Кузнецова С.А., Михайлов А.Г., Скворцова Г.П., Александрова Н.Б., Лебедева А.Б. Интенсификация процесса водной экстракции арабиногалактана из древесины лиственницы // Химия растительного сырья. 2005. №1. C. 53-58.

92. Seixas F.L., Fukuda D.L., Turbiani F.R.B., Garcia P.S., Petkowicz C.L.D.O., Jagadevan S., Gimenes M.L. Extraction of pectin from passion fruit peel (Passiflora edulis f.flavicarpa) by microwave-induced heating // Food Hydrocolloids. 2014. V. 38, Pp. 189-192.

93. Xie J.H., Xie M.Y., Shen M.Y., Nie S.P., Li C., Wang Y.X. Optimisation of microwave-assisted extraction of polysaccharides from Cyclocarya paliurus (Batal.) Iljinskaja using response surface methodology // Journal of the Science of Food and Agriculture. 2010. V. 90, N8. Pp. 1353-1360.

94. Liu Z., Dang J., Wang Q., Yu M., Jiang L., Mei L., Shao Y., Tao Y. Optimization of polysaccharides from Lycium ruthenicum fruit using RSM and its anti-oxidant activity // International Journal of Biological Macromolecules. 2013. V. 61, Pp. 127-134.

95. Monteil-Rivera F., Huang G.H., Paquet L., Deschamps S., Beaulieu C., Hawari J. Microwave-assisted extraction of lignin from triticale straw: Optimization and microwave effects // Bioresource Technology. 2012. V. 104, Pp. 775-782.

96. Monteil-Rivera F., Phuong M., Ye M., Halasz A., Hawari J. Isolation and characterization of herbaceous lignins for applications in biomaterials // Industrial Crops and Products. 2013. V. 41, N1. Pp. 356-364.

97. Smiglak M., Pringle J.M., Lu X., Han L., Zhang S., Gao H., MacFarlane D.R., Rogers R.D. Ionic liquids for energy, materials, and medicine // Chemical Communications. 2014. V. 50, N66. Pp. 9228-9250.

98. Swatloski R.P., Spear S.K., Holbrey J.D., Rogers R.D. Dissolution of cellose with ionic liquids // Journal of the American Chemical Society. 2002. V. 124, N18. Pp. 4974-4975.

99. Muhammad N., Man Z., Bustam Khalil M.A. Ionic liquid - a future solvent for the enhanced uses of wood biomass // European Journal of Wood and Wood Products. 2012. V. 70, N1-3. Pp. 125-133.

100. Vadivambal R., Jayas D.S. Changes in quality of microwave-treated agricultural products - a review // Biosystems Engineering. 2007. V. 98, N1. Pp. 1-16.

101. Gasmalla M.A.A., Yang R., Amadou I., Hua X. Nutritional composition of Stevia rebaudiana bertoni leaf: Effect of drying method // Tropical Journal of Pharmaceutical Research. 2014. V. 13, N1. Pp. 61-65.

102. Hamrouni-Sellami I., Rahali F.Z., Rebey I.B., Bourgou S., Limam F., Marzouk B. Total Phenolics, Flavonoids, and Antioxidant Activity of Sage (Salvia officinalis L.) Plants as Affected by Different Drying Methods // Food and Bioprocess Technology. 2013. V. 6, N3. Pp. 806-817.

103. Sellami I.H., Rebey I.B., Sriti J., Rahali F.Z., Limam F., Marzouk B. Drying Sage (Salvia officinalis L.) Plants and Its Effects on Content, Chemical Composition, and Radical Scavenging Activity of the Essential Oil // Food and Bioprocess Technology. 2012. V. 5, N8. Pp. 2978-2989. 
104. Pirbalouti A.G., Mahdad E., Craker L. Effects of drying methods on qualitative and quantitative properties of essential oil of two basil landraces // Food Chemistry. 2013. V. 141, N3. Pp. 2440-2449.

105. Lander T.A., Dadonaite B., Monro A.K. Microwave drying of plant material for herbarium specimens and genetic analysis // Taxon. 2013. V. 62, N4. Pp. 790-797.

106. Mosqueda M.R., Tabil L.G., Meda V. Physico-chemical characteristics of microwave-dried wheat distillers grain with solubles // The Journal of microwave power and electromagnetic energy : a publication of the International Microwave Power Institute. 2013. V. 47, N3. Pp. 155-176.

107. Palade P.A., Leuca T., Bandici L. Aspects regarding the processing of semi-manufactured wood in a microwave field // Journal of Electrical and Electronics Engineering. 2011. V. 4, N1. Pp. 153-156.

108. Hansson L., Antti A.L. The effect of microwave drying on Norway spruce woods strength: A comparison with conventional drying // Journal of Materials Processing Technology. 2003. V. 141, N1. Pp. 41-50.

109. Bartholme M., Avramidis G., Viöl W., Kharazipour A. Microwave drying of wet processed wood fibre insulating boards // European Journal of Wood and Wood Products. 2009. V. 67, N3. Pp. 357-360.

110. Torgovnikov G. Microwave Wood Processing. 2010 [Электронный ресурc]. URL: http://www.microwavewoodprocessing.com/.

111. Torgovnikov G., Vinden P. Microwave wood modification technology and its applications // Forest Products Journal. 2010. V. 60, N2. Pp. 173-182.

112. Bundhoo Z.M.A., Mudhoo A., Mohee R. Promising unconventional pretreatments for lignocellulosic biomass // Critical Reviews in Environmental Science and Technology. 2013. V. 43, N20. Pp. 2140-2211.

113. Miura M., Kaga H., Sakurai A., Kakuchi T., Takahashi K. Rapid pyrolysis of wood block by microwave heating // Journal of Analytical and Applied Pyrolysis. 2004. V. 71, N1. Pp. 187-199.

114. Баннова Е.А., Китаева Н.К., Мерков С.М., Мучкина М.В., Залозная Е.П., Мартынов П.Н. Изучение способа получения гидрофобного сорбента на основе модифицированного торфа // Сорбционные и хроматографические процессы. 2013. Т. 13, №1. С. 60-68.

115. Fu Y., Wang L., Zhou Z. Microwave regeneration of field-spent granular activated carbon from power plants // 2011 International Conference on Energy, Environment and Sustainable Development, ICEESD 2011. Shanghai, 2012. Pp. 2065-2070.

116. Nguyen T.D., Moon J.I., Song J.H., Kim T.N. Synthesis of activated carbon from rice husk using microwave heating induced KOH activation // Korean Journal of Materials Research. 2012. V. 22, N6. Pp. 321-327.

117. Nóbrega J.A., Pirola C., Fialho L.L., Rota G., De Campos Jordão C.E.K.M.A., Pollo F. Microwave-assisted digestion of organic samples: How simple can it become? // Talanta. 2012. V. 98, Pp. 272-276.

118. Tokalioğlu Ş. Determination of trace elements in commonly consumed medicinal herbs by ICP-MS and multivariate analysis // Food Chemistry. 2012. V. 134, N4. Pp. 2504-2508.

119. Liu H.W., Qin Z.H., Xie H.L., Cao S. Study on the determination of 28 inorganic elements in sunflower seeds by ICPOES/ICP-MS // Spectroscopy and Spectral Analysis. 2013. V. 33, N1. Pp. 224-227.

120. Singh R., Tiwari S., Srivastava M., Shukla A. Experimental study on the performance of microwave assisted hydrogen peroxide $\left(\mathrm{H}_{2} \mathrm{O}_{2}\right)$ pretreatment of rice straw // Agricultural Engineering International: CIGR Journal. 2014. V. 16, N1. Pp. 173-181.

121. Verma P., Watanabe T., Honda Y. Microwave-assisted pretreatment of woody biomass with ammonium molybdate activated by $\mathrm{H}_{2} \mathrm{O}_{2} / /$ Bioresource Technology. 2011. V. 102, N4. Pp. 3941-3945.

122. Inan H., Turkay O., Akkiris C. Microwave and microwave-alkali effect on barley straw for total sugar yield // International Journal of Global Warming. 2014. V. 6, N2-3. Pp. 212-221.

123. El-Zawawy W.K., Ibrahim M.M., Abdel-Fattah Y.R., Soliman N.A., Mahmoud M.M. Acid and enzyme hydrolysis to convert pretreated lignocellulosic materials into glucose for ethanol production // Carbohydrate Polymers. 2011. V. 84 , N3. Pp. 865-871.

124. Кисурин И.В., Арапов К.А., Гущин П.А., Иванов Е.В., Винокуров В.А. Перспективы использования микроволнового излучения в процессе переработки целлюлозосодержащего сырья // Башкирский химический журнал. 2010. №3. С. 167-170.

125. Fan S.P., Jiang L.Q., Chia C.H., Fang Z., Zakaria S., Chee K.L. High yield production of sugars from deproteinated palm kernel cake under microwave irradiation via dilute sulfuric acid hydrolysis // Bioresource Technology. 2014. V. 153. Pp. 69-78.

126. Катраков И.Б., Базарнова Н.Г., Маркин В.И., Воробьева Е.А., Стригунов В.В. Обработка микроволновым излучением древесины сосны // Новые достижения в химии и химической технологии растительного сырья : материалы V Всерос. конф. с междунар. участием. Барнаул, 2012. С. 113.

127. Tsubaki S., Ozaki Y., Azuma J. Microwave-Assisted Autohydrolysis of Prunus mume Stone for Extraction of Polysaccharides and Phenolic Compounds // Journal of Food Science. 2010. V. 75, N2. Pp. C152-C159.

128. Singh V., Kumar P., Sanghi R. Use of microwave irradiation in the grafting modification of the polysaccharides - A review // Progress in Polymer Science (Oxford). 2012. V. 37, N2. Pp. 340-364.

129. Goetz L.A., Sladky J.P., Ragauskas A.J. Analysis of microwave vs. thermally assisted grafting of poly(methyl-vinyl ether co-maleic acid)-polyethylene glycol to birch kraft pulp // Holzforschung. 2009. V. 63, N4. Pp. 414-417.

130. Dziak J. Application of radio-frequency wave and micro-wave devices in drying and bleaching of wooden pulp // Applied Thermal Engineering. 2008. V. 28, N10. Pp. 1189-1195.

131. Wu C.J., Zhao C.S., Li J., Chen K.F. The effect of microwave treatment on the hydrogen peroxide bleaching of soda-AQ wheat straw pulp // 2011 International Conference on Chemical Engineering and Advanced Materials, CEAM. 2011. V. 236-238. C. 1307-1312.

132. Chadlia A., Farouk M.M. Rapid homogeneous esterification of cellulose extracted from Posidonia induced by microwave irradiation // Journal of Applied Polymer Science. 2011. V. 119, N6. Pp. 3372-3381. 
133. Joly N., Granet R., Krausz P. Crosslinking of cellulose by olefin metathesis // Journal of Carbohydrate Chemistry. 2003. V. 22, N1. Pp. 47-55.

134. Patent 19938501 (DE). Carboxymethylcellulose production, useful in chromatography or as intermediate in biotechnology, pharmacy, paper and food industries comprises electromagnetic irradiation of cellulose / Thielking H., Koch W., Nachtkamp K., Ondruschka B., Nuechter M., Heinze U., Klemm D. 2001.

135. Zhang G.L., Zhang L., Deng H., Sun P. Preparation and characterization of sodium carboxymethyl cellulose from cotton stalk using microwave heating // Journal of Chemical Technology and Biotechnology. 2011. V. 86, N4. Pp. 584-589.

136. Peng X.W., Ren J.L., Zhong L.X., Cao X.F., Sun R.C. Microwave-induced synthesis of carboxymethyl hemicelluloses and their rheological properties // Journal of Agricultural and Food Chemistry. 2011. V. 59, N2. Pp. 570-576.

137. Shi H., Yin Y., Jiao S. Preparation and characterization of carboxymethyl starch under ultrasound-microwave synergistic interaction // Journal of Applied Polymer Science. 2014. V. 131, N20. DOI: 10.1002/app.40906

138. Singh A.V., Nath L.K., Guha M., Kumar R. Microwave Assisted Synthesis and Evaluation of Cross-Linked Carboxymethylated Sago Starch as Superdisintegrant // Pharmacology \& Pharmacy. 2011. V. 2, N1. Pp. $42-46$.

139. Guo Y., Zhou J., Wang Y., Zhang L., Lin X. An efficient transformation of cellulose into cellulose carbamates assisted by microwave irradiation // Cellulose. 2010. V. 17, N6. Pp. 1115-1125.

140. Rowell R.M. Handbook of Wood Chemistry and Wood Composites. New York, 2005. 473 p.

141. Hill C.A.S. Wood Modification: Chemical, Thermal and Other Processes. John Wiley \& Sons Ltd, 2006. 248 p.

142. Базарнова Н.Г., Катраков И.Б., Маркин В.И. Химическое модифицирование древесины // Российский химический журнал. 2004. T. XLVIII, №3. С. 108-115.

143. Базарнова Н.Г., Маркин В.И., Колосов П.В., Катраков И.Б., Калюта Е.В., Чепрасова М.Ю. Методы получения лигноуглеводных композиций из химически модифицированного растительного сырья // Российский химический журнал. 2011. Т. 55, №1. С. 4-9.

144. Brelid L.P., Simonson R., Risman P.O. Acetylation of solid wood using microwave heating: Part 1: Studies of dielectric properties // Holz als Roh- und Werkstoff. 1999. V. 57, N4. Pp. 259-263.

145. Brelid P.L., Simonson R. Acetylation of solid wood using microwave heating: Part 2. Experiments in laboratory scale // Holz als Roh- und Werkstoff. 1999. V. 57, N5. Pp. 383-389.

146. Brelid P.L. The influence of post-treatments on acetyl content for removal of chemicals after acetylation // Holz als Rohund Werkstoff. 2002. V. 60, N2. Pp. 92-95.

147. Маркин В.И., Базарнова Н.Г., Галочкин А.И. О взаимодействии лигноуглеводных материалов с монохлоруксусной кислотой // Химия растительного сырья. 1997. №1. С. 26-28.

148. Патент №2130947 (РФ). Способ карбоксиметилирования лигноуглеводных материалов / Галочкин А.И., Маркин В.И., Базарнова Н.Г., Заставенко Н.В., Крестьянникова Н.С. 1999.

149. Маркин В.И., Базарнова Н.Г., Галочкин А.И. Изучение влияния предобработки на карбоксиметилирование древесины березы в среде изопропилового спирта // Пластические массы. 1998. №7. С. 31-34.

150. Маркин В.И. Карбоксиметилирование растительного сырья. Теория и практика. Барнаул, 2010. 167 с.

151. Маркин В.И., Галочкин А.И., Базарнова Н.Г., Крестьянникова Н.С. Карбоксиметилирование биомассы надземной части тростника в условиях механохимической активации без растворителя // Химия в интересах устойчивого развития. 1997. Т. 5, №5. С. 523-528.

152. Базарнова Н.Г., Маркин В.И., Галочкин А.И., Токарева И.В. Алкилирование лигноуглеводных материалов с использованием механохимического метода // Химия в интересах устойчивого развития. 1998. №6. С. $223-227$.

153. Патент №2131884 (RU). Способ карбоксиметилирования лигноуглеводных материалов / Базарнова Н.Г., Маркин В.И., Галочкин А.И., Токарева И.В. 1999.

154. Патент №2135517 (РФ). Способ карбоксиметилирования лигноуглеводных материалов / Базарнова Н.Г., Токарева И.В., Галочкин А.И., Маркин В.И. 1999.

155. Патент №2393169 (РФ). Способ получения карбоксиметилированного лигноуглеводного материала под воздействием микроволнового излучения / Маркин В.И., Михаилиди А.М., Базарнова Н.Г. 2010.

156. Чепрасова М.Ю., Михаилиди А.М., Котолевский И.В., Маркин В.И., Базарнова Н.Г. Карбоксиметилирование древесины сосны под воздействием микроволнового излучения // Новые достижения в химии и химической технологии растительного сырья : матер. IV Всерос. конф. Барнаул, 2009. Кн. 1. С. 100-101.

157. Чепрасова М.Ю., Маркин В.И., Базарнова Н.Г., Коталевский И.В. Карбоксиметилирование древесины под воздействием микроволнового излучения в среде различных растворителей // Химия растительного сырья. 2011. №1. С. 77-80.

158. Михаилиди А.М., Маркин В.И. Карбоксиметилирование древесины под воздействием СВЧ-излучения // Новые достижения в химии и химической технологии растительного сырья : мат. III Всерос. конф. Барнаул, 2007. С. 90-91.

159. Чепрасова М.Ю. Карбоксиметилирование растительного сырья под воздействием микроволнового излучения : дис. ... канд. хим. наук. Красноярск, 2012. 121 с.

160. Cheprasova M.Y., Markin V.I., Bazarnova N.G., Kotalevskii I.V. Carboxymethylation of Wood in Different Solvents by the Action of Microwave Radiation // Russian Journal of Bioorganic Chemistry. 2012. V. 38, N7. Pp. 726-729.

161. Маркин В.И. Исследование карбоксиметилирования древесины суспензионным способом: дис. ... канд. хим. наук. Красноярск, 1999. 159 с.

162. Чепрасова М.Ю., Маркин В.И., Базарнова Н.Г., Калюта Е.В., Морозова В.С. Молекулярный состав целлюлозы, карбоксиметилированной в составе древесины под воздействием микроволнового излучения в среде различных растворителей // Химия растительного сырья. 2011. №2. С. 87-90.

163. Маркин В.И., Базарнова Н.Г., Колосов П.В., Чепрасова М.Ю., Москова Ю.С. Карбоксиметилирование древесины сосны после ее обработки в системе «уксусная кислота - пероксид водорода - вода - катализатор» под воздействием микроволнового излучения // Химия растительного сырья. 2012. №4. С. 55-60. 
164. Markin V.I., Bazarnova N.G., Kolosov P.V., Cheprasova M.Y., Moskova Y.S. Carboxymethylation of pine wood subjected to microwave irradiation after pretreatment in an «acetic acid - hydrogen peroxide - water - catalyst» system // Russian Journal of Bioorganic Chemistry. 2013. V. 39, N7. Pp. 699-703.

165. Маркин В.И., Чепрасова М.Ю., Базарнова Н.Г., Фролова Е.О. Получение калиевой соли карбоксиметилированной древесины сосны в условиях микроволнового излучения // Химия растительного сырья. 2013. №2. С. 69-72.

166. Markin V.I., Cheprasova M.Y., Bazarnova N.G., Frolova E.O. Pine wood carboxymethylation under microwave radiation // Russian Journal of Bioorganic Chemistry. 2014. V. 40, N7. Pp. 733-736.

167. Чепрасова М.Ю., Маркин В.И., Базарнова Н.Г., Калюта Е.В. Карбоксиметилирование целлюлозы в составе растительного сырья под воздействием микроволнового излучения. Барнаул, 2013. 32 p.

168. Чепрасова М.Ю., Маркин В.И. Карбоксиметилирование растительного сырья под воздействием микроволнового излучения. Барнаул, 2014. 96 с.

169. Sutradhar P., Debnath N., Saha M. Microwave-assisted rapid synthesis of alumina nanoparticles using tea, coffee and triphala extracts // Advances in Manufacturing. 2013. V. 1, N4. Pp. 357-361.

170. Bhuvanasree S.R., Harini D., Rajaram A., Rajaram R. Rapid synthesis of gold nanoparticles with Cissus quadrangularis extract using microwave irradiation // Spectrochimica Acta - Part A: Molecular and Biomolecular Spectroscopy. 2013. V. 106. Pp. 190-196.

171. Zheng Z., Pan H., Huang Y., Chung Y.H., Zhang X., Feng H. Rapid liquefaction of wood in polyhydric alcohols under microwave heating and its liquefied products for preparation of rigid polyurethane foam // Open Materials Science Journal. 2011. V. 5, Pp. 1-8.

172. Gabriel C., Gabriel S., Grant E.H., Halstead B.S.J., Michael P., Mingos D. Dielectric parameters relevant to microwave dielectric heating // Chemical Society Reviews. 1998. V. 27, N3. Pp. 213-223.

173. Hessel V., Cravotto G., Fitzpatrick P., Patil B.S., Lang J., Bonrath W. Industrial applications of plasma, microwave and ultrasound techniques: Nitrogen-fixation and hydrogenation reactions // Chemical Engineering and Processing: Process Intensification. 2013. V. 71, Pp. 19-30.

Поступило в редакцию 25 декабря 2013 2.

После переработки 15 сентября 2014 г.

Markin V.I., Cheprasova M.Iu., Bazarnova N.G. BASIC DIRECTIONS OF USE MICROWAVE RADIATION IN THE PROCESSING OF PLANT RAW MATERIAL (REVIEW)

Altai State University, Lenina ave., 61, Barnaul, 656049 (Poccuя), e-mail: markin@chemwood.asu.ru

The use of microwave radiation in the chemistry of plant raw materials in the last decade attracted the attention of a growing number of scientists. The present review publications in this field in recent years, the number of which increases exponentially. The main field of application of microwave radiation in the chemistry and technology of vegetable raw materials: extraction of natural plant facilities for the low molecular weight compounds of different classes in the individual state and the form of compositions (eg, essential oils); selection of high structural biopolymers (cellulose, lignin, hemicellulose); The drying process plant facilities; pyrolysis of wood; hydrolysis of high-molecular components of plant raw materials; chemical modification of vegetable origin of biopolymers to obtain ethers and esters and other derivatives; chemical modification of plant raw materials without prior separation into individual components and some other processes. The efficiency of the microwave radiation in these processes. It is noted that the microwave radiation is generally conducted considerably faster process and significantly reduces energy costs. The examples of processes described in the industry. Processes and mechanisms that occur when exposed to microwave radiation plant material is currently not well understood and require further investigation.

Keywords: microwave radiation, plant material, wood, cellulose, lignin, hemicellulose, extractives, essential oils, ionic liquids, green chemistry, chemical modification, dry-tion, pyrolysis, hydrolysis, delignification.

\footnotetext{
* Corresponding author.
} 


\section{References}

1. Sheldon R.A. Chemical Society Reviews, 2012, vol. 41, no. 4, pp. 1437-1451.

2. Höfer R., Bigorra J. Green Chemistry Letters and Reviews, 2008, vol. 1, no. 2, pp. 79-97.

3. Michael D., Mingos P., Baghurst D.R. Chemical Society Reviews, 1991, vol. 20, no. 1, pp. 1-47.

4. Metaxas A.C., Meredith R.J. Industrial Microwave Heating. P. Peregrinus, 1983.

5. Kingston H.M., Jassie L.B. Introduction to Microwave Sample Preparation: Theory and Practice. American Chemical Society, 1988.

6. Strauss C.R., Trainor R.W. Australian Journal of Chemistry, 1995, vol. 48, no. 10, pp. $1665-1692$.

7. Rakhmankulov D.L., Bikbulatov I.X., Shulasv N.S., Shavtukova S.Iu. Mikrovolnovoe izluchenie i intensifikatsiia khimicheskikh protsessov. [Microwave radiation and intensification of chemical processes]. Moscow, 2003,220 p. (in Russ.).

8. Meredith R.J. Engineers Handbook of Industrial Microwave Heating. The Institution of Engineering and Technology, 1998.

9. Ishii T.K. Handbook of Microwave Technology, Volume 1: Components and Devices. Academic Press, 1995.

10. Ishii T.K. Handbook of Microwave Technology. Volume 2, Applications. Academic Press, 1995.

11. Datta A.K. Handbook of Microwave Technology for Food Application (Food Science and Technology). 2001.536 p.

12. Fernández Y., Arenillas A., Menéndez J.Á. Advances in induction and microwave heating of mineral and organic materials. Intech, 2011. 766 p.

13. Chandra U. Microwave Heating. Intech, 2011. 382 p.

14. The Development and Application of Microwave Heating. 2012.

15. Sanghi R., Singh V. Green Chemistry for Environmental Remediation. CRC Press, Taylor \& Francis Group, 2012.

16. Paré J.R.J., Bélanger J.M.R., Stafford S.S. TrAC - Trends in Analytical Chemistry, 1994, vol. 13, no. 4, pp. $176-184$.

17. Microwave-Enhanced Chemistry. Fundamentals, Sample Preparation and Applications. Washington: American Chemical Society:, 1997. 772 p.

18. Kubrakova I.V. Uspekhi khimii, 2002, vol. 71, no. 4, pp. 327-340. (in Russ.).

19. Kubrakova I.V., Miasoedova G.V., Eremin S.A., Pletnev I.V., Mokhodoeva O.B., Morozova V.A., Khachatrian K.S. Metody i ob"ekty khimicheskogo analiza, 2006, vol. 1, no. 1, pp. 27-34. (in Russ.).

20. Camel V. TrAC - Trends in Analytical Chemistry, 2000, vol. 19, no. 4, pp. 229-248.

21. Gedye R., Smith F., Westaway K., Ali H., Baldisera L., Laberge L., Rousell J. Tetrahedron Letters, 1986, vol. 27, no. 3, pp. 279-282.

22. Giguere R.J., Bray T.L., Duncan S.M., Majetich G. Tetrahedron Letters, 1986, vol. 27, no. 41, pp. $4945-4948$.

23. Romanova N.N., Gravis A.G., Zyk N.V. Uspekhi khimii, 2005, vol. 74, no. 11, pp. 1159-1105. (in Russ.).

24. Lidström P., Tierney J., Wathey B., Westman J. Tetrahedron, 2001, vol. 57, no. 45, pp. 9225-9283.

25. Kappe C.O., Stadler A. Microwaves in Organic and Medicinal Chemistry. WILEY-VCH, 2005.422 p.

26. Kappe C.O., Dallinger D., Murphree S.S. Practical Microwave Synthesis for Organic Chemists. WILEY-VCH, 2009. 307 p.

27. Strauss C. Green Chemistry, 1999, August, pp. G94-G96.

28. Kappe C.O., Dallinger D. Molecular Diversity, 2009, vol. 13, no. 2, pp. 71-193.

29. Mallakpour S., Rafiee Z. Iranian Polymer Journal (English Edition), 2008, vol. 17, no. 12, pp. 907-935.

30. Bogdal D., Prociak A. Microwave-enhanced polymer chemistry and technology. Blackwell Publishing Ltd, 2007.284 p.

31. Chemat F., Cravotto G. Microwave-assisted Extraction for Bioactive Compounds. Theory and Practice. Springer US, 2013.

32. Destandau E., Michel T., Elfakir C. Microwave-assisted extraction. Cambridge, 2013, pp. $113-156$.

33. Delazar A., Nahar L., Hamedeyazdan S., Sarker S. Natural Products Isolation, 2012, vol. 864, pp. 89-115.

34. Kokolakis A.K., Golfinopoulos S.K. Natural Product Communications, 2013, vol. 8, no. 10, pp. $1493-1504$.

35. Chua L.S. Journal of Ethnopharmacology, 2013, vol. 150, no. 3, pp. 805-817.

36. Das A.K., Mandal V., Mandal S.C. Phytochemical Analysis, 2014, vol. 25, no. 1, pp. 1-12.

37. Mason T.J., Chemat F., Vinatoru M. Current Organic Chemistry, 2011, vol. 15, no. 2, pp. $237-247$.

38. Mahibalan S., Sharma R., Vyas A., Basha S.A., Begum A.S. Journal of the Indian Chemical Society, 2013, vol. 90, no. 12, pp. 2199-2205.

39. Delgado-Torre M.P., Ferreiro-Vera C., Priego-Capote F., Pérez-Juan P.M., Luque De Castro M.D. Journal of Agricultural and Food Chemistry, 2012, vol. 60, no. 12, pp. 3051-3060.

40. Karabegović I.T., Stojičević S.S., Veličković D.T., Todorović Z.B., Nikolić N.T., Lazić M.L. Industrial Crops and Products, 2014, vol. 54, pp. 142-148.

41. Xu W., Chu K., Li H., Zhang Y., Zheng H., Chen R., Chen L. Molecules, 2012, vol. 17, no. 12, pp. 14323-14335.

42. Bai L.S., Yang Y., Lv D.D. Zhong yao cai = Zhongyaocai = Journal of Chinese medicinal materials, 2012, vol. 35, no. 6, pp. 977-980.

43. Wataniyakul P., Pavasant P., Goto M., Shotipruk A. Bioresource Technology, 2012, vol. 124, Pp. 18-22.

44. Yan Z., da-Yun S., Jing-Shu Z., Hong-Li Z. African Journal of Biotechnology, 2011, vol. 10, no. 65, pp. $14583-14586$.

45. Zhang L., Wang Y., Wu D., Xu M., Chen J. Molecules, 2011, vol. 16, no. 6, pp. 4428-4437.

46. Yang Y.C., Li J., Zu Y.G., Fu Y.J., Luo M., Wu N., Liu X.L. Food Chemistry, 2010, vol. 122, no. 1, pp. 373-380.

47. Zou T., Wu H., Li H., Jia Q., Song G. Journal of Separation Science, 2013, vol. 36, no. 20 , pp. 3457-3462.

48. Yan M.M., Liu W., Fu Y.J., Zu Y.G., Chen C.Y., Luo M. Food Chemistry, 2010, vol. 119, no. 4, pp. 1663-1670.

49. Das A.K., Mandal V., Mandal S.C. Phytochemical Analysis, 2013, vol. 24, no. 3, pp. $230-247$.

50. Koptelova E.N., Kutakova N.A., Tret'iakov S.I. Khimiia rastitel'nogo syr'ia, 2013, no. 4, pp. 159-164. (in Russ.).

51. Chumnanpaisont N., Niamnuy C., Devahastin S. Chemical Engineering Science, 2014, vol. 116, Pp. 442-451.

52. Boldor D., Kanitkar A., Terigar B.G., Leonardi C., Lima M., Breitenbeck G.A. Environmental Science and Technology, 2010, vol. 44, no. 10, pp. 4019-4025. 
53. Ma C.H., Liu T.T., Yang L., Zu Y.G., Chen X., Zhang L., Zhang Y., Zhao C. Journal of Chromatography A., 2011, vol. 1218 , no. 48 , pp. 8573-8580.

54. Brodie G., Harris G., Jacob M.V., Sheehan M., Yin L. Journal of Microwave Power and Electromagnetic Energy, 2011, vol. 45, no. 4, pp. 178-187.

55. Verma S.C., Jain C.L., Kumari A., Padhi M.M., Devalla R.B. Journal of Separation Science, 2013, vol. 36, no. 7, pp. $1255-1262$.

56. Xia E.Q., Wang B.W., Xu X.R., Zhu L., Song Y., Li H.B. International Journal of Molecular Sciences, 2011, vol. 12, no. 8, pp. 5319-5329.

57. Puttarak P., Panichayupakaranant P. Pharmaceutical Biology, 2012, vol. 50, no. 12, pp. 1508-1512.

58. Chen T., Sun X., Xiao W., Liu X., Zhang W., Ma K., Zhu Y. Medicinal Chemistry Research, 2010, vol. 19, no. 8, pp. $732-742$.

59. Liu W., Zhou C.L., Zhao J., Chen D., Li Q.H. Acta Scientiarum Polonorum, Technologia Alimentaria, 2014, vol. 13, no. 2 , pp. $155-168$.

60. Tang B., Bi W., Tian M., Row K.H. Journal of Chromatography B: Analytical Technologies in the Biomedical and Life Sciences, 2012, vol. 904, Pp. 1-21.

61. Li X.J., Yu H.M., Gao C., Zu Y.G., Wang W., Luo M., Gu C.B., Zhao C.J., Fu Y.J. Journal of Separation Science, 2012, vol. 35, no. 24, pp. 3600-3608.

62. Sun S., Zhai Y.J., Sun Y., Zhang Y.P., Liu H., Wang X.H., Yu A.M., Zhang H.Q. Gaodeng Xuexiao Huaxue Xuebao/Chemical Journal of Chinese Universities, 2010, vol. 31, no. 3, pp. 468-472.

63. Liu X., Wang Y., Kong J., Nie C., Lin X. Analytical Methods, 2012, vol. 4, no. 4, pp. 1012-1018.

64. Yuan Y., Wang Y., Xu R., Huang M., Zeng H. Analyst, 2011, vol. 136, no. 11, pp. 2294-2305.

65. Zeng H., Wang Y., Kong J., Nie C., Yuan Y. Talanta, 2010, vol. 83, no. 2, pp. 582-590.

66. Gómez N.E., Witte L. Journal of Chemical Ecology, 2001, vol. 27, no. 11, pp. 2351-2359.

67. Chemat F., Perino-Issartier S., Petitcolas E., Fernandez X. Analytical and Bioanalytical Chemistry, 2012, vol. 404, no. 3, pp. 679-682.

68. Stashenko E.E., Jaramillo B.E., Martínez J.R. Journal of Chromatography A., 2004, vol. 1025, no. 1, pp. $93-103$.

69. Ferhat M.A., Tigrine-Kordjani N., Chemat S., Meklati B.Y., Chemat F. Chromatographia, 2007, vol. 65, no. 3-4, pp. $217-222$.

70. Mircioaga N., Calinescu I. Revista de Chimie, 2011, vol. 62, no. 11, pp. 1073-1076.

71. Jiang C., Sun Y., Zhu X., Gao Y., Wang L., Wang J., Wu L., Song D. Journal of Separation Science, 2010, vol. 33, no. 17-18, pp. 2784-2790.

72. Azar P., Porgham-Daryasari A., Saber-Tehrani M., Soleimani M. Acta Chromatographica, 2012, vol. 24, no. 1, pp. 75-84.

73. Ma C.H., Yang L., Zu Y.G., Liu T.T. Food Chemistry, 2012, vol. 134, no. 4, pp. 2532-2539.

74. Boukhari F., Tigrine-Kordjani N., Youcef Meklati B. Helvetica Chimica Acta, 2013, vol. 96, no. 6, pp. 1168-1175.

75. Li X.J., Wang W., Luo M., Li C.Y., Zu Y.G., Mu P.S., Fu Y.J. Food Chemistry, 2012, vol. 133, no. 2, pp. $437-444$.

76. Azar P.A., Tehrani M.S., Hosain S.W., Khalilzadeh M.A., Zanousi M.B.P. Asian Journal of Chemistry, 2012, vol. 24, no. 11 , pp. 5388-5390.

77. Uysal B., Sozmen F., Buyuktas B.S. Natural Product Communications, 2010, vol. 5, no. 1, pp. 111-114.

78. Bajpai V.K., Sharma A., Kim S.H., Baek K.H. Food Technology and Biotechnology, 2013, vol. 51, no. 3, pp. $360-369$.

79. Orio L., Cravotto G., Binello A., Pignata G., Nicola S., Chemat F. Journal of the Science of Food and Agriculture, 2012, vol. 92 , no. 15 , pp. 3085-3090.

80. Gholivand M.B., Piryaei M., Abolghasemi M.M. Journal of Separation Science, 2013, vol. 36, no. 5, pp. 872-877.

81. Benkaci-Ali F., Akloul R., Boukenouche A., Pauw E.D. Journal of Essential Oil-Bearing Plants, 2013, vol. 16, no. 6, pp. 781-794.

82. Périno-Issartier S., Abert-Vian M., Petitcolas E., Chemat F. Chromatographia, 2010, vol. 72, no. 3-4, pp. 347-350.

83. Miletić P., Grujić R., Marjanović-Balaban Ž. Chemical Industry and Chemical Engineering Quarterly, 2009, vol. 15, no. 1, pp. 37-39.

84. Jiao J., Gai Q.Y., Fu Y.J., Zu Y.G., Luo M., Zhao C.J., Li C.Y. Separation and Purification Technology, 2013, vol. 107, pp. 228-237.

85. Punegov V.V., Kostromin V.I., Fomina M.G., Zainullin V.G., Iushkova E.A., Belykh D.V., Chukicheva I.Iu., Zainullin G.G. Khimiia rastitel'nogo syr'ia, 2014, no. 1, pp. 125-130. (in Russ.).

86. Zhang G., Hu M., He L., Fu P., Wang L., Zhou J. Food and Bioproducts Processing, 2013, vol. 91, no. 2, pp. $158-168$.

87. Peng F., Peng P., Xu F., Sun R.C. Biotechnology Advances, 2012, vol. 30, no. 4, pp. 879-903.

88. Tahmouzi S. International Journal of Biological Macromolecules, 2014, vol. 69, pp. 523-531.

89. Panthapulakkal S., Pakharenko V., Sain M. Journal of Polymers and the Environment, 2013, vol. 21, no. 4, pp. $917-929$.

90. Panthapulakkal S., Sain M. Chemistry \& Materials Science, 2013, vol. 1, no. 6, pp. 38-55.

91. Kuznetsova S.A., Mikhailov A.G., Skvortsova G.P., Aleksandrova N.B., Lebedeva A.B. Khimiia rastitel'nogo syr'ia, 2005 no. 1, pp. 53-58. (in Russ.).

92. Seixas F.L., Fukuda D.L., Turbiani F.R.B., Garcia P.S., Petkowicz C.L.D.O., Jagadevan S., Gimenes M.L. Food Hydrocolloids, 2014, vol. 38, pp. 189-192.

93. Xie J.H., Xie M.Y., Shen M.Y., Nie S.P., Li C., Wang Y.X. Journal of the Science of Food and Agriculture, 2010, vol. 90, no. 8, pp. 1353-1360.

94. Liu Z., Dang J., Wang Q., Yu M., Jiang L., Mei L., Shao Y., Tao Y. International Journal of Biological Macromolecules, 2013, vol. 61, Pp. 127-134.

95. Monteil-Rivera F., Huang G.H., Paquet L., Deschamps S., Beaulieu C., Hawari J. Bioresource Technology, 2012, vol. 104, Pp. 775-782.

96. Monteil-Rivera F., Phuong M., Ye M., Halasz A., Hawari J. Industrial Crops and Products, 2013, vol. 41, no. 1, pp. 356-364. 
97. Smiglak M., Pringle J.M., Lu X., Han L., Zhang S., Gao H., MacFarlane D.R., Rogers R.D. Chemical Communications, 2014, vol. 50, no. 66, pp. 9228-9250.

98. Swatloski R.P., Spear S.K., Holbrey J.D., Rogers R.D. Journal of the American Chemical Society, 2002, vol. 124, no. 18, pp. 4974-4975.

99. Muhammad N., Man Z., Bustam Khalil M.A. European Journal of Wood and Wood Products, 2012, vol. 70, no. 1-3, pp. $125-133$.

100. Vadivambal R., Jayas D.S. Biosystems Engineering, 2007, vol. 98, no. 1, pp. 1-16.

101. Gasmalla M.A.A., Yang R., Amadou I., Hua X. Tropical Journal of Pharmaceutical Research, 2014, vol. 13, no. 1, pp. 61-65.

102. Hamrouni-Sellami I., Rahali F.Z., Rebey I.B., Bourgou S., Limam F., Marzouk B. Food and Bioprocess Technology, 2013, vol. 6, no. 3, pp. 806-817.

103. Sellami I.H., Rebey I.B., Sriti J., Rahali F.Z., Limam F., Marzouk B. Food and Bioprocess Technology, 2012, vol. 5, no. 8, pp. 2978-2989.

104. Pirbalouti A.G., Mahdad E., Craker L. Food Chemistry, 2013, vol. 141, no. 3, pp. 2440-2449.

105. Lander T.A., Dadonaite B., Monro A.K. Taxon, 2013, vol. 62, no. 4, pp. 790-797.

106. Mosqueda M.R., Tabil L.G., Meda V. The Journal of microwave power and electromagnetic energy : a publication of the International Microwave Power Institute, 2013, vol. 47, no. 3, pp. 155-176.

107. Palade P.A., Leuca T., Bandici L. Journal of Electrical and Electronics Engineering, 2011, vol. 4, no. 1, pp. $153-156$.

108. Hansson L., Antti A.L. Journal of Materials Processing Technology,. 2003, vol. 141, no. 1, pp. 41-50.

109. Bartholme M., Avramidis G., Viöl W., Kharazipour A. European Journal of Wood and Wood Products, 2009, vol. 67, no. 3, pp. 357-360.

110. Torgovnikov G. Microwave Wood Processing. 2010 [Электронный pecypc]. URL: http://www.microwavewoodprocessing.com/.

111. Torgovnikov G., Vinden P. Forest Products Journal, 2010, vol. 60, no. 2, pp. 173-182.

112. Bundhoo Z.M.A., Mudhoo A., Mohee R. Critical Reviews in Environmental Science and Technology, 2013, vol. 43, no. 20, pp. 2140-2211.

113. Miura M., Kaga H., Sakurai A., Kakuchi T., Takahashi K. Journal of Analytical and Applied Pyrolysis, 2004, vol. 71, no. 1, pp. 187-199.

114. Bannova E.A., Kitaeva N.K., Merkov S.M., Muchkina M.V., Zaloznaia E.P., Martynov P.N. Sorbtsionnye $i$ khromatograficheskie protsessy, 2013, vol. 13, no. 1, pp. 60-68. (in Russ.).

115. Fu Y., Wang L., Zhou Z. 2011 International Conference on Energy, Environment and Sustainable Development, ICEESD 2011. Shanghai, 2012, pp. 2065-2070.

116. Nguyen T.D., Moon J.I., Song J.H., Kim T.N. Korean Journal of Materials Research6 2012, vol. 22, no. 6, pp. 321-327.

117. Nóbrega J.A., Pirola C., Fialho L.L., Rota G., De Campos Jordão C.E.K.M.A., Pollo F. Talanta, 2012, vol. 98, pp. $272-276$.

118. Tokalioğlu, Ş. Food Chemistry, 2012, vol. 134, no. 4, pp. 2504-2508.

119. Liu H.W., Qin Z.H., Xie H.L., Cao S. Spectroscopy and Spectral Analysis, 2013, vol. 33, no. 1, pp. $224-227$.

120. Singh R., Tiwari S., Srivastava M., Shukla A. Agricultural Engineering International: CIGR Journal, 2014, vol. 16, no. 1, pp. $173-181$.

121. Verma P., Watanabe T., Honda Y. Bioresource Technology, 2011, vol. 102, no. 4, pp. 3941-3945.

122. Inan H., Turkay O., Akkiris C. International Journal of Global Warming, 2014, vol. 6, no. 2-3, pp. 212-221.

123. El-Zawawy W.K., Ibrahim M.M., Abdel-Fattah Y.R., Soliman N.A., Mahmoud M.M. Carbohydrate Polymers, 2011, vol. 84, no. 3, pp. 865-871.

124. Kisurin I.V., Arapov K.A., Gushchin P.A., Ivanov E.V., Vinokurov V.A. Bashkirskii khimicheskii zhurnal, 2010, no. 3, pp. 167-170. (in Russ.).

125. Fan S.P., Jiang L.Q., Chia C.H., Fang Z., Zakaria S., Chee K.L. Bioresource Technology, 2014, vol. 153, pp. 69-78.

126. Katrakov I.B., Bazarnova N.G., Markin V.I., Vorob'eva E.A., Strigunov V.V. Novye dostizheniia v khimii i khimicheskoi tekhnologii rastitel'nogo syr'ia : materialy V Vseros. konf. s mezhdunar. uchastiem. [New advances in chemistry and chemical engineering plant raw material: the V All-Russian Conference with international participation]. Barnaul, 2012, pp. 113. (in Russ.).

127. Tsubaki S., Ozaki Y., Azuma J. Journal of Food Science, 2010, vol. 75, no. 2, pp. C152-C159.

128. Singh V., Kumar P., Sanghi R. Progress in Polymer Science (Oxford), 2012, vol. 37, no. 2, pp. 340-364.

129. Goetz L.A., Sladky J.P., Ragauskas A.J. Holzforschung, 2009, vol. 63, no. 4, pp. 414-417.

130. Dziak J. Applied Thermal Engineering, 2008, vol. 28, no. 10, pp. 1189-1195.

131. Wu C.J., Zhao C.S., Li J., Chen K.F. 2011 International Conference on Chemical Engineering and Advanced Materials, CEAM. 2011, vol. 236-238. pp. 1307-1312.

132. Chadlia A., Farouk M.M. Journal of Applied Polymer Science, 2011, vol. 119, no. 6, pp. 3372-3381.

133. Joly N., Granet R., Krausz P. Journal of Carbohydrate Chemistry, 2003, vol. 22, no. 1, pp. 47-55.

134. Patent 19938501 (DE). C 2001.

135. Zhang G.L., Zhang L., Deng H., Sun P. Journal of Chemical Technology and Biotechnology, 2011, vol. 86, no. 4, pp. 584-589.

136. Peng X.W., Ren J.L., Zhong L.X., Cao X.F., Sun R.C. Journal of Agricultural and Food Chemistry, 2011, vol. 59, no. 2, pp. 570-576.

137. Shi H., Yin Y., Jiao S. Journal of Applied Polymer Science, 2014, vol. 131, no. 20. DOI: 10.1002/app.40906

138. Singh A.V., Nath L.K., Guha M., Kumar R. Pharmacology \& Pharmacy, 2011, vol. 2, no. 1, pp. 42-46.

139. Guo Y., Zhou J., Wang Y., Zhang L., Lin X. Cellulose, 2010, vol. 17, no. 6, pp. 1115-1125.

140. Rowell R.M. Handbook of Wood Chemistry and Wood Composites. New York: CRC Press, 2005. 473 p.

141. Hill C.A.S. Wood Modification: Chemical, Thermal and Other Processes. John Wiley \& Sons Ltd, 2006. 248 p.

142. Bazarnova N.G., Katrakov I.B., Markin V.I. Rossiiskii khimicheskii zhurnal, 2004, vol. XLVIII, no. 3, pp. 108-115. (in Russ.). 
143. Bazarnova N.G., Markin V.I., Kolosov P.V., Katrakov I.B., Kaliuta E.V., Cheprasova M.Iu. Rossiiskii khimicheskii zhurnal, 2011, vol. 55, no. 1, pp. 4-9. (in Russ.).

144. Brelid L.P., Simonson R., Risman P.O. Holz als Roh- und Werkstoff, 1999, vol. 57, no. 4, pp. 259-263.

145. Brelid P.L., Simonson R. Holz als Roh- und Werkstoff, 1999, vol. 57, no. 5, pp. 383-389.

146. Brelid P.L. Holz als Roh- und Werkstoff, 2002, vol. 60, no. 2, pp. 92-95.

147. Markin V.I., Bazarnova H.G., Galochkin A.I. Khimiia rastitel'nogo syr'ia, 1997, no. 1, pp. 26-28. (in Russ.).

148. Patent 2130947 (RU). 1999. (in Russ.).

149. Markin V.I., Bazarnova N.G., Galochkin A.I. Plasticheskie massy, 1998, no. 7, pp. 31-34. (in Russ.).

150. Markin V.I. Karboksimetilirovanie rastitel'nogo syr'ia. Teoriia i praktika. [Carboxymethylation of vegetable raw materials. Theory and practice]. Barnaul, 2010, 167 p. (in Russ.).

151. Markin V.I., Galochkin A.I., Bazarnova N.G., Krest'iannikova N.S. Khimiia v interesakh ustoichivogo razvitiia, 1997, vol. 5, no. 5, pp. 523-528. (in Russ.).

152. Bazarnova N.G., Markin V.I., Galochkin A.I., Tokareva I.V. Khimiia v interesakh ustoichivogo razvitiia, 1998, no. 6, pp. 223-227. (in Russ.).

153. Patent 2131884 (RU). 1999. (in Russ.).

154. Patent 2135517 (RU). 1999. (in Russ.).

155. Patent 2393169 (RU). 2010. (in Russ.).

156. Cheprasova M.Iu., Mikhailidi A.M., Kotolevskii I.V., Markin V.I., Bazarnova N.G. Novye dostizheniia $v$ khimii $i$ khimicheskoi tekhnologii rastitel'nogo syr'ia : mater. IV Vseros. konf. [New advances in chemistry and chemical engineering plant raw materials: materials of the IV All-Russian Conference]. Barnaul, 2009, vol. 1. pp. 100-101. (in Russ.).

157. Cheprasova M.Iu., Markin V.I., Bazarnova N.G., Kotalevskii I.V. Khimiia rastitel'nogo syr'ia, 2011, no. 1, pp. 77-80. (in Russ.).

158. Mikhailidi A.M., Markin V.I. Novye dostizheniia v khimii i khimicheskoi tekhnologii rastitel'nogo syria : mater. III Vseros. konf. [New advances in chemistry and chemical engineering plant raw materials: materials of the III All-Russian Conference]. Barnaul, 2007, pp. 90-91. (in Russ.).

159. Cheprasova M.Iu. Karboksimetilirovanie rastitel'nogo syr'ia pod vozdeistviem mikrovolnovogo izlucheniia : dis. ... kand. khim. nauk. [Carboxymethylation vegetable raw materials under microwave irradiation: The thesis Ph.D. in Chemistry]. Krasnoyarsk, 2012, 121 p. (in Russ.).

160. Cheprasova M.Y., Markin V.I., Bazarnova N.G., Kotalevskii I.V. Russian Journal of Bioorganic Chemistry, 2012, vol. 38, no. 7, pp. 726-729.

161. Markin V.I. Issledovanie karboksimetilirovaniia drevesiny suspenzionnym sposobom: dis. ... kand. khim. nauk. [The study carboxymethylation wood slurry process: the dissertation Ph.D. in Chemistry]. Krasnoyarsk, 1999, 159 p. (in Russ.).

162. Cheprasova M.Iu., Markin V.I., Bazarnova N.G., Kaliuta E.V., Morozova V.S. Khimiia rastitel'nogo syr'ia, 2011, no. 2, pp. 87-90. (in Russ.).

163. Markin V.I., Bazarnova N.G., Kolosov P.V., Cheprasova M.Iu., Moskova Iu.S. Khimiia rastitel'nogo syr'ia, 2012, no. 4, pp. 55-60. (in Russ.).

164. Markin V.I., Bazarnova N.G., Kolosov P.V., Cheprasova M.Y., Moskova Y.S. Russian Journal of Bioorganic Chemistry, 2013, vol. 39, no. 7, pp. 699-703.

165. Markin V.I., Cheprasova M.Iu., Bazarnova N.G., Frolova E.O. Khimiia rastitel'nogo syr'ia, 2013, no. 2, pp. 69-72. (in Russ.).

166. Markin V.I., Cheprasova M.Y., Bazarnova N.G., Frolova E.O. Russian Journal of Bioorganic Chemistry, 2014, vol. 40, no. 7, pp. 733-736.

167. Cheprasova M.Iu., Markin V.I., Bazarnova N.G., Kaliuta E.V. Karboksimetilirovanie tselliulozy v sostave rastitel'nogo syr'ia pod vozdeistviem mikrovolnovogo izlucheniia. [Carboxymethylation of the cellulose raw material composed of vegetable under microwave irradiation]. Barnaul, 2013, 32 p. (in Russ.).

168. Cheprasova M.Iu., Markin V.I. Karboksimetilirovanie rastitel'nogo syr'ia pod vozdeistviem mikrovolnovogo izlucheniia. [Carboxymethylation of plant raw materials under microwave irradiation]. Barnaul, 2014. 96 p. (in Russ.).

169. Sutradhar P., Debnath N., Saha M. Advances in Manufacturing, 2013, vol. 1, no. 4, pp. 357-361.

170. Bhuvanasree S.R., Harini D., Rajaram A., Rajaram R. Spectrochimica Acta - Part A: Molecular and Biomolecular Spectroscopy, 2013, vol. 106, pp. 190-196.

171. Zheng Z., Pan H., Huang Y., Chung Y.H., Zhang X., Feng H. Open Materials Science Journal, 2011, vol. 5,pp. 1-8.

172. Gabriel C., Gabriel S., Grant E.H., Halstead B.S.J., Michael P., Mingos D. Chemical Society Reviews, 1998, vol. 27, no. 3, pp. 213-223.

173. Hessel V., Cravotto G., Fitzpatrick P., Patil B.S., Lang J., Bonrath W. Chemical Engineering and Processing: Process Intensification, 2013, vol. 71, pp. 19-30. 